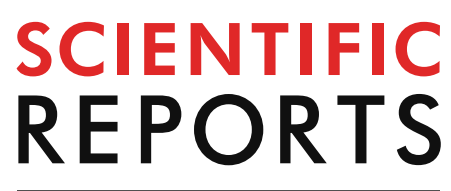

natureresearch

Check for updates

\title{
Characterization and selection of functional yeast strains during sourdough fermentation of different cereal wholegrain flours
}

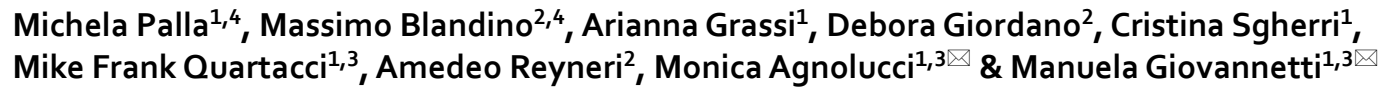

The increasing demand for healthy baked goods boosted studies on sourdough microbiota with beneficial metabolic traits, to be used as potential functional starters. Here, 139 yeasts isolated from cereal-based fermented foods were in vitro characterized for their phytase and antioxidant activities. The molecular characterization at strain level of the best 39 performing isolates showed that they did not derive from cross contamination by baker's yeast. Afterwards, the 39 isolates were in vivo analyzed for their leavening ability, phytase activity and polyphenols content using five different wholegrain flours, obtained from conventional and pigmented common wheat, emmer and hullless barley. Combining these findings, through multivariate permutation analysis, we identified the 2 best performing strains, which resulted diverse for each flour. Doughs singly inoculated with the selected strains were further analyzed for their antioxidant capacity, phenolic acids, xanthophylls and anthocyanins content. All the selected yeasts significantly increased the total antioxidant activity, the soluble, free and conjugated, forms of phenolic acids and anthocyanins of fermented doughs. This study revealed the importance of a specific selection of yeast strains for wholegrain flours obtained from different cereals or cultivars, in order to enhance the pro-technological, nutritional and nutraceutical traits of fermented doughs.

Fermentation is one of the oldest methods used by humans since ancient times for preserving foods and improving their organoleptic properties. More than 5,000 fermented foods and beverages are produced all over the world, from wine, beer and vinegar to cheese, yogurt, sourdough bread, olives, sausages, kimchi and miso ${ }^{1}$. Fermentation consists of the biochemical modification of raw materials, promoted by a complex and stable consortium of microorganisms, which mainly transform sugars into simple acids, alcohols and carbon dioxide, improving flavor, texture and aroma, and prolonging the shelf-life of the fermented products ${ }^{2}$. During fermentation, a wide range of secondary metabolites, including vitamins, polyols, antioxidants and bioactive compounds are also produced by microbial communities, enhancing the nutritional and nutraceutical values of the final products $^{3}$.

Among fermented foods, sourdough bread is one of the most important baked goods derived from cereal fermentation ${ }^{4}$. The estimated annual pro capita intake of bread in European countries is reported to range from 46 (Sweden, Great Britain, Finland and Austria) to $100 \mathrm{~kg}$ (Greece, Portugal, Spain and Italy) ${ }^{5}$, and about 30 to $50 \%$ of bread is manufactured using sourdough ${ }^{6}$. Sourdough is a mixture of cereal flour and water, fermented by a complex biological ecosystem, consisting of lactic acid bacteria (LAB) and yeasts which interact with each other, often establishing stable associations and contributing to the beneficial properties of sourdough breads ${ }^{7}$. Each sourdough harbors different LAB and yeast communities, whose diversity depends on the type of flour and water, processing environments and various process parameters such as temperature, time of fermentation, number of refreshments and so on. Saccharomyces cerevisiae is the yeast species most frequently retrieved, followed

${ }^{1}$ Department of Agriculture, Food and Environment, University of Pisa, Via del Borghetto 80, 56124 Pisa, Italy. ${ }^{2}$ Department of Agricultural, Forest and Food Sciences (DISAFA), Università Degli Studi Di Torino, Largo Braccini 2, 10095 Grugliasco, TO, Italy. ${ }^{3}$ Interdepartmental Research Centre "Nutraceuticals and Food for Health", University of Pisa, Pisa, Italy. ${ }^{4}$ These authors contributed equally: Michela Palla and Massimo Blandino. ${ }^{\square}$ email: monica.agnolucci@unipi.it; manuela.giovannetti@unipi.it 
by Kazachstania humilis and Wickerhamomyces anomalus ${ }^{8}$, while among LAB, Lactobacillus sanfranciscensis represents the dominant species ${ }^{9}$. Different species and strains may have different metabolic patterns, conferring specific properties to each sourdough bread. For example, some strains synthesize essential amino acids or vitamins, i.e. thiamine, vitamin $\mathrm{E}$ and folates, others produce prebiotic exopolysaccharides (EPS) and bioactive compounds such as polyphenols, organic acids, peptides and amino acid derivatives, i.e. $\gamma$-amino butyric acid $(\mathrm{GABA})^{10}$. Moreover, microbial strains may produce enzymes, i.e. proteases, phytases or lipases, and degrade anti-nutritional factors such as raffinose and phytic acid which chelates iron, calcium, magnesium and zinc, thus depleting their bioavailability ${ }^{10}$.

In recent years, the increasing demand for healthy foods boosted studies on sourdough microbiota with beneficial metabolic features to be used as potential functional starters for the production of baked goods. Most works focused on the functional and nutritional features of sourdough as the consequence of LAB metabolism ${ }^{10,11}$, though an increasing number of studies highlighted the important role of yeast metabolism on such beneficial traits $^{8,12}$. Indeed, several yeast strains are able to produce different vitamins $s^{13,14}$ and antioxidant compounds ${ }^{15}$, ${ }^{16}$, and to degrade antinutritional substances such as phytates ${ }^{17,18}$. Recently, Palla et al. ${ }^{19}$, investigating the protechnological, nutritional and functional traits of 78 Tuscan sourdough yeasts, detected different $S$. cerevisiae strains showing phytase activity and antioxidant properties.

Wholegrain flour has a high content of bioactive compounds, in particular phenolic acids, the main responsible of the antioxidant activity of cereal grains, flours and derived baked products ${ }^{20}$. Moreover, anthocyanins and carotenoids, phytochemicals with a strong antioxidant activity, are also attracting an increased interest among wholegrain products derived from different cereals such as rice ${ }^{21}$, maize ${ }^{22}$ and, more recently, wheat ${ }^{23,24}$. These bioactive compounds are generally found in conventional red-grained common wheat (Triticum aestivum L. spp. aestivum) varieties; however, purple or blue-pigmented grain cultivars show a high content of anthocyanins in both pericarp and aleurone layers, respectively ${ }^{23}$. Carotenoids are responsible for the yellow colour of the endosperm and flour of durum wheat (Triticum turgidum spp. durum (Desf.) Husn.) and other diploid and tetraploid Triticum species such as einkorn (T. monococcum L. spp. monococcum) and emmer (T. turgidum spp. dicoccum (Schrank) Thell). Carotenoids have been detected in high concentrations also in yellow-grained cultivars of common wheat ${ }^{23}$. Barley, in particular hull-less barley (Hordeum vulgare L. var. nudum Hook), is an excellent source of soluble and insoluble fibers and shows a high antioxidant activity, its flour representing a functional ingredient for bakery products ${ }^{25}$.

The overall objective of this work was the selection of yeast strains with interesting functional and nutritional traits to be used as functional starters for the production of healthy breads. With this aim, 139 yeast strains isolated from cereal-based fermented foods and drinks, were characterized and selected for their pro-technological, functional and molecular traits by in vitro and in vivo screening. Five different wholegrain flours were used: a conventional red-grained wheat variety, a yellow-grained wheat variety rich in carotenoids, a blue-grained wheat variety rich in anthocyanins, a winter emmer variety and a hull-less spring barley variety.

\section{Results}

Functional characterization of flours. In order to evaluate the functional properties of the five wholegrain flours, their antioxidant capacity, phenolic acid, xanthophyll and anthocyanin contents were analyzed (Supplementary Table S1 online). Hull-less barley flour showed the highest antioxidant activity, considering both ferric reducing antioxidant power (FRAP) and ABTS [2,2'-Azino-bis (3-ethylbenzthiazoline-6-sulfonic acid)] methods, and a cell wall-bound phenolic acids (CWBPA) content significantly higher compared to the other cultivars, except for the blue-grained wheat. The content of soluble phenolic acids (SPAs) was the lowest one due to a significantly lower concentration of sinapic acid if compared to the other cereals. On the other hand, emmer flour had overall the lowest FRAP antioxidant activity and CWBPA content, and a significantly lower concentration of lutein and zeaxanthin compared to the yellow-grain common wheat flour. Furthermore, emmer flour had a SPA content, in particularly sinapic acid, significantly higher than hull-less barley and yellow-grained common wheat flours. The blue-grained cultivar Skorpion showed a significantly higher concentration of SPAs and CWBPAs than the other common wheat flours. Although the blue-grained and yellow-grained wheat cultivars showed a higher content of anthocyanins and xanthophyll, respectively, the antioxidant activity measured with both methods was not significantly different among the common wheat cultivars.

In vitro functional characterization of yeast isolates. Phytase activity, evaluated on 139 yeast isolates, was detected in $77 \%$ of isolates, $40 \%$ of which showed a halo zone higher than $2 \mathrm{~mm}$ (Supplementary Table S2 online). The results of the antioxidant activity showed a high variability among the 139 yeast isolates: $75 \%$ of them exhibited a radical scavenging capacity, ranging from $65.11 \pm 14.43$ to $0.34 \pm 0.34 \mathrm{nmol} \mathrm{TEAC} / \mathrm{mL}$ (Trolox equivalents of antioxidant capacity).

Molecular characterization of selected yeast isolates. According to in vitro preliminary results, 55 yeast isolates showing the highest values for phytase and/or antioxidant activities were selected. Among them, 31 isolates had been previously molecularly characterized ${ }^{19}$. The other 24 isolates, still of unknown identity, were analyzed by the amplification of the D1/D2 domains of the 26S rRNA gene and sequencing. An amplicon of about $600 \mathrm{bp}$ was obtained for each isolate, as expected. The amplicons were sequenced and affiliated to fungal species using BLAST and phylogenetic trees analyses (Table 1). Sequences were affiliated with Candida parapsilosis (46\%), S. cerevisiae (17\%), Pichia fermentans (8\%), Prillingera fragicola (8\%), Candida sake (4\%), Candida inconspicua (4\%), Torulaspora quercuum (4\%), Rhodotorula mucilaginosa (4\%) and Cutaneotrichosporon curvatus $(4 \%)$. 


\begin{tabular}{|c|c|c|c|c|}
\hline Isolate & GeneBank Accession $\mathrm{N}^{\circ}$ & Identification & Identity (\%) & $\begin{array}{l}\text { Most closely related GeneBank } \\
\text { sequences }\end{array}$ \\
\hline BL2 & MT269548 & Prillingera fragicola CBS:8898 & $99 \%$ & NG_058427 \\
\hline BL3 & MT269550 & Candida sake CBS:5690 & $100 \%$ & KY106734 \\
\hline BL4 & MT269549 & Prillingera fragicola CBS: 8898 & $99 \%$ & NG_058427 \\
\hline BL5 & MT269551 & Saccharomyces cerevisiae A60 & $100 \%$ & KM589486 \\
\hline BL7 & MT269552 & Saccharomyces cerevisiae CBS:2962 & $100 \%$ & KY109317 \\
\hline BL10 & MT269555 & Candida inconspicua CBS:2833 & $100 \%$ & KY106513 \\
\hline BL11 & MT269556 & Pichia fermentans CBS: 1876 & $99.66 \%$ & KY108811 \\
\hline BL12 & MT269558 & Torulaspora quercuum CBS:11403 & $100 \%$ & NG_058415 \\
\hline BL14 & MT269557 & Pichia fermentans CBS:1876 & $100 \%$ & KY108811 \\
\hline BL16 & MT269559 & Rhodotorula mucilaginosa CBS:482 & $99.83 \%$ & KY109140 \\
\hline BL19 & MT269560 & Cutaneotrichosporon curvatum CBS:570 & $100 \%$ & AJ555468 \\
\hline GTS3Y & MT269561 & Candida parapsilosis CBS:7156 & $99.49 \%$ & KY106673 \\
\hline GTS6Y & MT269562 & Candida parapsilosis CBS:7156 & $100 \%$ & KY106673 \\
\hline GTS9Y & MT269563 & Candida parapsilosis CBS:7156 & $100 \%$ & KY106673 \\
\hline GTS11Y & MT269564 & Candida parapsilosis CBS:7156 & $100 \%$ & KY106673 \\
\hline GTS12Y & MT269565 & Candida parapsilosis CBS:7156 & $100 \%$ & KY106673 \\
\hline GTS18Y & MT269566 & Candida parapsilosis CBS:7156 & $99.67 \%$ & KY106673 \\
\hline GTS20Y & MT269567 & Candida parapsilosis CBS:7156 & $100 \%$ & KY106673 \\
\hline GTSXY & MT269553 & Saccharomyces cerevisiae CBS:2962 & $99.67 \%$ & KY109317 \\
\hline GTW10Y & MT269568 & Candida parapsilosis CBS:7156 & $100 \%$ & KY106673 \\
\hline GTW13Y & MT269569 & Candida parapsilosis CBS:7156 & $100 \%$ & KY106673 \\
\hline GTW14Y & MT269570 & Candida parapsilosis CBS:7156 & $100 \%$ & KY106673 \\
\hline GTW15Y & MT269571 & Candida parapsilosis CBS:7156 & $100 \%$ & KY106673 \\
\hline W9DY & MT269554 & Saccharomyces cerevisiae CBS:2962 & $100 \%$ & KY109317 \\
\hline
\end{tabular}

Table 1. Phylogenetic identification of 24 yeast isolates showing optimal functional traits in vitro.

On the basis of the molecular identification, eight out of the 24 isolates were selected as belonging to species commonly found in sourdoughs (S. cerevisiae, P. fermentans, C. sake and T. quercuum) and further characterized at the strain level by inter-delta regions analysis, together with the 31 already characterized. The dendrogram, obtained comparing the inter-delta profiles of such isolates, along with the profiles of the two commercial baker's yeasts, showed a high intraspecific diversity, discriminating 20 S. cerevisiae biotypes (Supplementary Fig. S1 online). It is interesting to note that none of our isolates shared the profile with the two commercial baker's yeast strains.

Leavening ability of selected yeast strains. The 39 molecularly characterized isolates were further analyzed for their leavening ability by in vivo screening using the five wholegrain flours. Results are reported in Fig. 1. All strains inoculated in wheat and emmer flours, except C. sake IMA BL3, showed leavening ability ranging from $3.34 \pm 0.18 \mathrm{~cm}^{3} / \mathrm{h}$ in the case of the conventional red-grained wheat $\mathrm{cv}$. Aubusson flour fermented by $S$. cerevisiae IMA D17Y to $0.27 \pm 0.03 \mathrm{~cm}^{3} / \mathrm{h}$ for the yellow-grained common wheat $\mathrm{cv}$. Bona Vita flour fermented by $P$. fermentans IMA BL11 (Figs. 1a-d). Only $33 \%$ of our yeasts inoculated in barley flour showed such a capacity $\left(\leq 0.51 \mathrm{~cm}^{3} / \mathrm{h}\right)$, while the commercial baker's yeasts did not show any leavening ability (Fig. 1e). Overall, the highest leavening performances were shown by yeasts belonging to the $S$. cerevisiae species. Moreover, 72, 82 and $72 \%$ of the strains inoculated into the common wheat Aubusson, Skorpion and Bona Vita, respectively, showed the same or a significantly higher leavening performance, compared to the commonly used commercial baker's yeasts. It is interesting to note that S. cerevisiae IMA D17Y, D4Y and L6Y showed the highest values of leavening ability in almost all the doughs.

The average $\mathrm{pH}$ values at the end of the fermentation were about $5.89 \pm 0.01$ in common wheat cultivars and in emmer fermented doughs, while doughs made using hull-less barley flours showed $\mathrm{pH}$ values generally lower (mean 5.56 \pm 0.01 ).

In vivo functional properties of selected yeast strains. For each flour, the 10 strains with the highest leavening ability were selected and analyzed for their phytase activity and polyphenol content by in vivo screening.

Phytase activity was determined on the water-salt soluble extract of fermented doughs by monitoring the rate of hydrolysis of $p$-nitrophenyl phosphate ( $p$-NPP). Results showed a high variability, ranging from $26.9 \pm 0.7$ to $2.8 \pm 1.4 \mathrm{U}$ among the doughs started with the different strains (Fig. 2), the highest values being reached in doughs obtained with the hull-less barley cv. Rondo flour. Moreover, 80 and $40 \%$ of strains inoculated in the red-grained cv. Aubusson (Fig. 2a) and blue-grained cv. Skorpion (Fig. 2c) flours, respectively, exhibited phytase activity values significantly higher compared to the commercial baker's yeast Zeus IBA. 


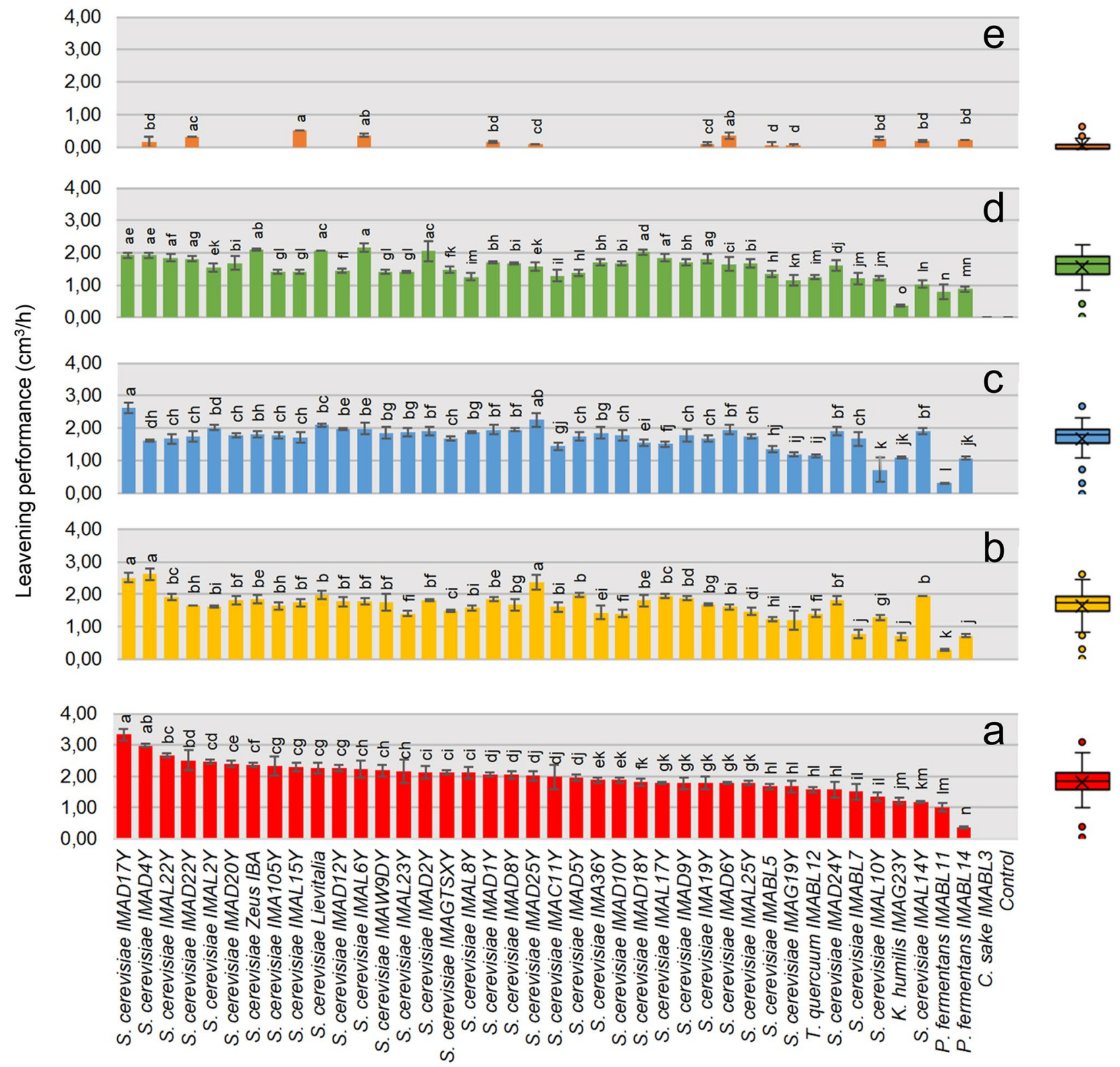

Figure 1. Leavening ability $\left(\mathrm{cm}^{3} / \mathrm{h}\right)$ of (a) conventional red-grained wheat variety T. aestivum L. cv. Aubusson, (b) yellow-grained wheat variety T. aestivum L. cv. Bona Vita, (c) blue-grained wheat variety T. aestivum L. cv. Skorpion, (d) winter emmer variety T. turgidum subsp. dicoccum var. Schrank, Giovanni Paolo and (e) hullless spring barley variety $H$. vulgare L. var. nudum Hook, Rondo fermented doughs individually inoculated with selected yeast strains. Control, Lievitalia and Zeus IBA represent doughs not inoculated and inoculated with commercial baker's yeasts, respectively. Bars of standard deviations are also represented. Data followed by the same letter do not differ (welch $=$ (a) 41.04, $p<0.001$; (b) 106.14, $p<0.001$; (c) $59.45, p<0.001$; (d) 64.21, $p<0.001$; (e) 207.46, $p<0.001$ ) Boxplot with mean $(x)$ and median (black line) are shown. White spots correspond to minimum and maximum values.

The analysis of the total phenol content was carried out on the methanolic extracts of fermented doughs by monitoring the reaction between phenols with the Folin-Ciocalteu reagent. Results showed that almost all the strains led to an increase in the total phenol content, ranging from $1.08 \pm 0.03$ to $0.68 \pm 0.01 \mathrm{mg}$ GAE/g (GAE: gallic acid equivalents) (Fig. 3). It is interesting to note that three strains for the conventional red-grained common wheat (Fig. 3a), three for the blue-grained cv. Skorpion (Fig. 3c), seven for emmer (Fig. 3d) and all strains for barley (Fig. 3e) sourdoughs showed polyphenol contents significantly higher than the commercial baker's yeast.

Combining the leavening ability, phytase activity and phenol content values through multivariate permutation analysis, the two best performing strains for each flour were identified (Fig. 4). In particular, S. cerevisiae IMA D20Y and D22Y (Fig. 4a), S. cerevisiae IMA L22Y and L17Y (Fig. 4b), S. cerevisiae IMA D8Y and L6Y (Fig. 4c), S. cerevisiae IMA L22Y and D18Y (Fig. 4d), S. cerevisiae IMA L15Y and L10Y (Fig. 4e) resulted the best performing 

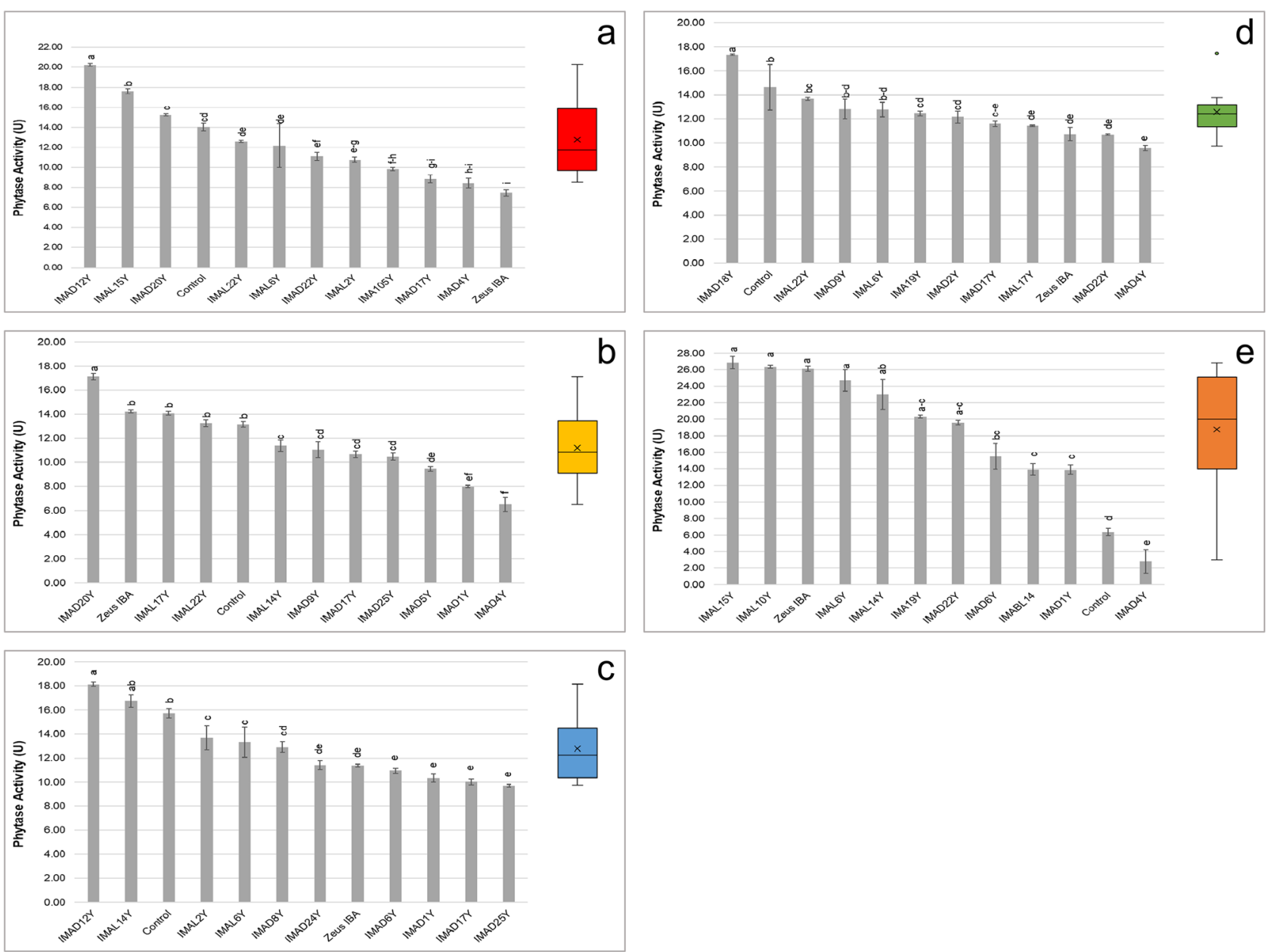

Figure 2. Phytase activity of (a) conventional red-grained wheat variety T. aestivum L. cv. Aubusson, (b) yellow-grained wheat variety T. aestivum L. cv. Bona Vita, (c) blue-grained wheat variety T. aestivum L. cv. Skorpion, (d) winter emmer variety T. turgidum subsp. dicoccum var. Schrank, Giovanni Paolo and (e) hull-less spring barley variety $H$. vulgare L. var. nudum Hook, Rondo fermented doughs individually inoculated with selected yeast strains. Control and Zeus IBA represent doughs not inoculated and inoculated with commercial baker's yeasts, respectively. One unit (U) of activity was defined as the amount of enzyme required to liberate $1 \mu \mathrm{mol} / \mathrm{min}$ of $\mathrm{p}$-nitrophenol under the assay conditions. Bars of standard deviations are also represented. Data followed by the same letter do not differ (welch $=$ (a) 246.16, $p<0.001 ;$ (c) 123.24, $p<0.001$; (d) 513.09, $p<0.001$; (e) 78.54, $p<0.001$; (b) F=70.73, $p<0.001$ ) Boxplot with mean $(x)$ and median (black line) are shown. White spots correspond to minimum and maximum values.

yeasts when inoculated in the red-grained wheat cv. Aubusson, yellow-grained wheat cv. Bona Vita, blue-grained wheat cv. Skorpion, emmer cv. Giovanni Paolo and barley cv. Rondo flours, respectively. Interestingly, the best performing yeast strains were different for each wholegrain flour.

Doughs singly inoculated with such yeast strains were further analyzed for their antioxidant capacity and phenolic acid, xanthophyll and anthocyanin contents. Fermentation with yeasts resulted in a significant increase in CWBPA content only for the conventional red-grained common wheat, although a significant effect on single phenolic acids was found in all the considered cereals (Table 2). The CWBPAs that increased after yeast fermentation were hydroxybenzoic and syringic acids (in all common wheat cv. and emmer), vanillic acid (in red-grained common wheat, emmer and barley), $p$-coumaric acid (only in emmer) and sinapic acid (only in blue-grained common wheat). Ferulic acid, the main CWBPAs detected in all cereals, showed significant changes in doughs obtained with the red-grained cv. Aubusson flour.

The strongest effect of yeast fermentation was detected on SPAs dough content: in all the considered wholegrain flours and for all the compared yeasts, fermentation resulted in significant increases in SPAs, compared with the relevant controls (Table 3). Significant effects were reported for all the compared cereal flours for sinapic, hydroxybenzoic and vanillic acids. Interestingly, significantly higher increases in SPAs were detected for emmer dough when inoculated with the L22Y strain.

Yeast fermentation did not affect lutein and zeaxanthin dough content, while it significantly increased total anthocyanin content (TAC) in the blue-grained common wheat flour (Table 4). No effect was reported for antioxidant capacity measured with the ABTS method. On the contrary, fermentation with some selected strains significantly increased antioxidant capacity measured with the FRAP method in all the wholegrain flours, with 

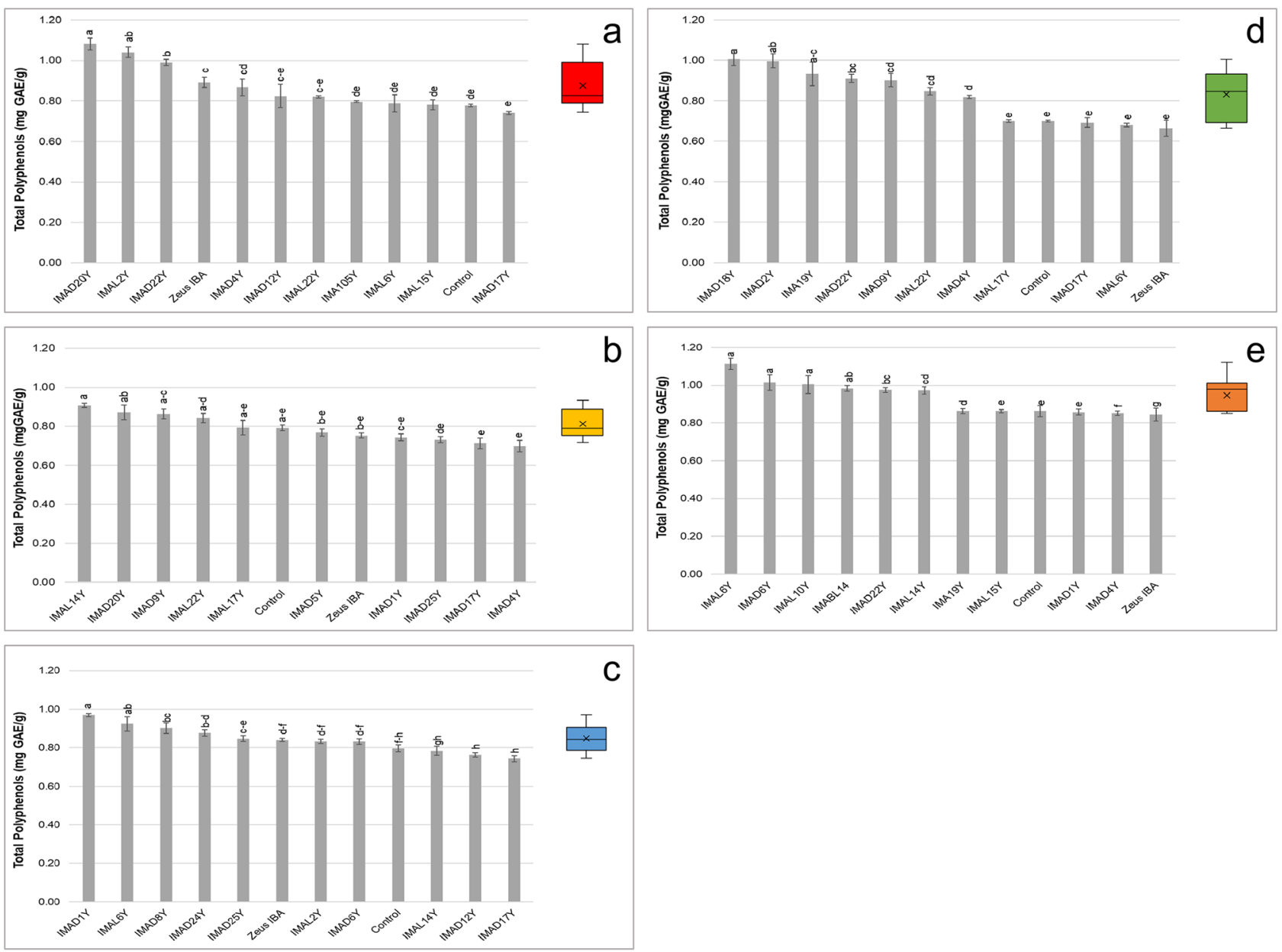

Figure 3. Total phenols (mg GAE/g) of (a) conventional red-grained wheat variety T. aestivum L. cv. Aubusson, (b) yellow-grained wheat variety T. aestivum L. cv. Bona Vita, (c) blue-grained wheat variety T. aestivum L. cv. Skorpion, (d) winter emmer variety T. turgidum subsp. dicoccum var. Schrank, Giovanni Paolo and (e) hull-less spring barley variety $H$. vulgare L. var. nudum Hook, Rondo fermented doughs individually inoculated with selected yeast strains. Control and Zeus IBA represent doughs not inoculated and inoculated with commercial baker's yeasts, respectively. Bars of standard deviations are also represented. Data followed by the same letter do not differ $($ welch $=(\mathbf{a}) 22.49, p<0.001$; (c) 21.82, $p<0.001$; (d) 27.12, $p<0.001$; (e) 144.63, $p<0.001$; (b) F=7.96, $p<0.001)$ Boxplot with mean $(x)$ and median (black line) are shown.

the exception of that obtained from the yellow-grain common wheat. It is interesting to note that barley flour fermented by the L10Y strain showed the highest content of antioxidant capacity. Moreover, L6Y and L22Y strains showed significantly higher antioxidant capacity compared to the controls when inoculated in blue-grained wheat cv. Skorpion and emmer flours.

\section{Discussion}

The increasing demand for healthy baked goods boosted studies on sourdough microbiota with beneficial metabolic traits, to be used as potential functional starters. The impact of fermentation technology on the functional properties has been disregarded so far, as most of the starter yeasts currently used are selected only for their peculiar leavening and other technological properties ${ }^{26}$. Here, we screened 139 yeast strains isolated from cerealbased fermented foods and drinks for their functional and nutritional traits, as affected by wholegrain flours obtained from five different cereals. Pro-technological, functional and molecular characterization allowed the selection of two yeast strains possessing, beyond a high leavening ability, the highest phytase and antioxidant activities, to be used as functional starters for the production of healthy baked goods.

The 139 yeasts were first in vitro characterized for their phytase and antioxidant activities. Phytic acid represents an abundant anti-nutritional factor in cereal flours which chelates minerals such as iron and zinc, depleting their bioavailability and uptake. Among our isolates, a high number of strains (77\%) exhibited the ability to solubilize phytate, consistently with previous data showing such an activity in several sourdough yeast isolates, belonging mainly to $S$. cerevisiae $e^{27,28}$ and in 13 out of 15 indigenous yeasts isolated from fermented foods ${ }^{29}$.

Over the past few years, the interest about the antioxidant properties of foods has strongly increased, as reactive oxygen species could be involved in many human diseases (e.g., cancer, diabetes, autoimmune conditions, etc. $)^{30}$. Recently, yeasts have been shown to enhance bioactive components in fermented food products by the 

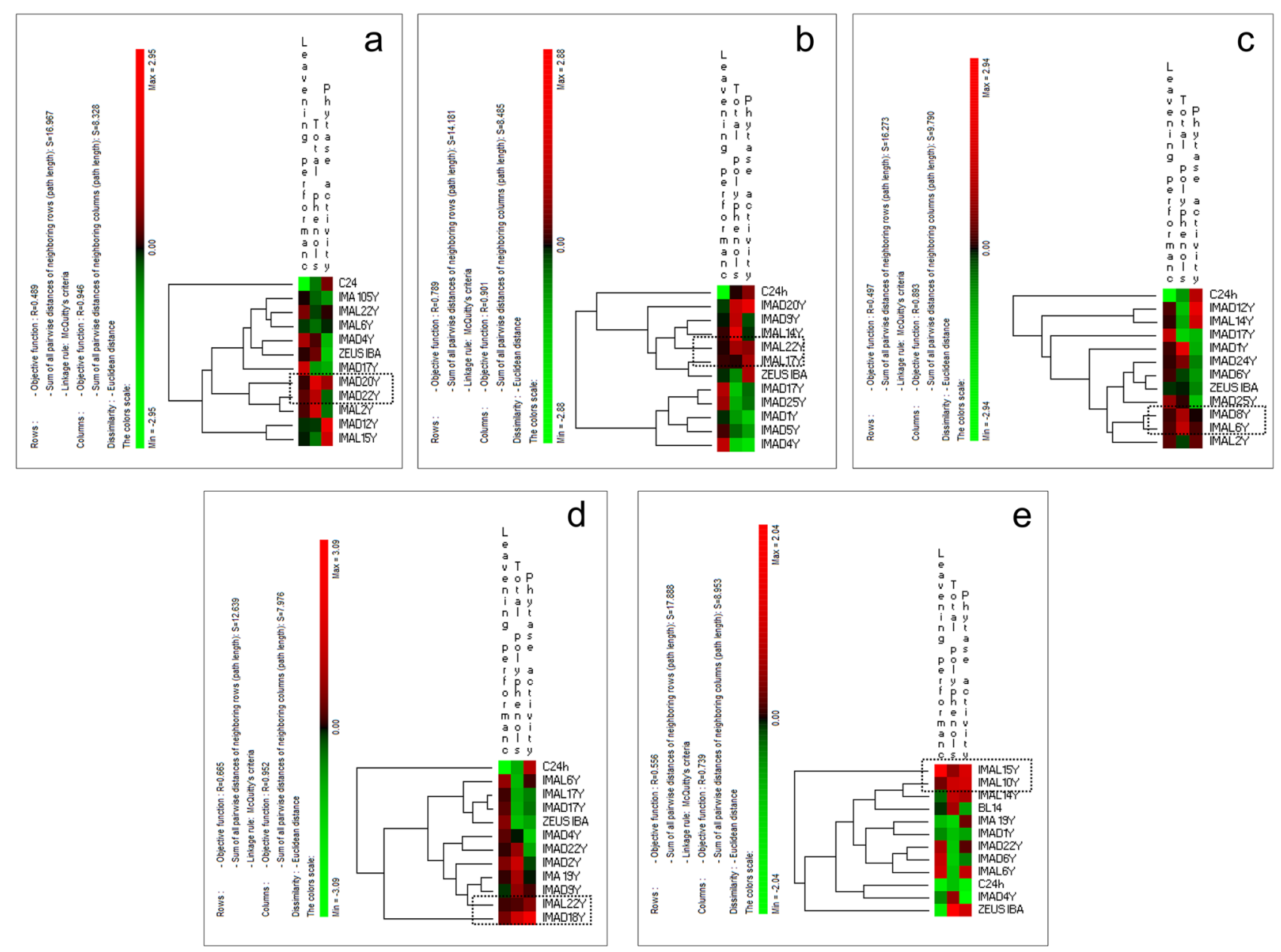

Figure 4. Leavening ability $\left(\mathrm{cm}^{3} / \mathrm{h}\right)$, phytase activity $(\mathrm{U})$ and total phenols (mg GAE/g) (a) conventional red-grained wheat variety T. aestivum L. cv. Aubusson, (b) yellow-grained wheat variety T. aestivum L. cv. Bona Vita, (c) blue-grained wheat variety T. aestivum L. cv. Skorpion, (d) winter emmer variety T. turgidum subsp. dicoccum var. Schrank, Giovanni Paolo and (e) hull-less spring barley variety H. vulgare L. var. nudum Hook, Rondo fermented doughs individually inoculated with selected yeast strains. Euclidean distance and McQuitty's criterion (weighted pair group method with averages) were used for clustering. Colours correspond to normalized mean data levels from low (green) to high (red). The colour scale, in terms of units of standard deviation, is shown on the left side. Strains marked by the dashed box are the best performing strains.

production of enzymes and metabolites that affect the antioxidant properties of baked goods ${ }^{31}$. Here, $75 \%$ of yeasts showed in vitro radical scavenging capability, with a high variability among them, consistently with data from Gazi et al. ${ }^{32}$ who, using the same method, found that 23 out of 25 yeast strains showed radical scavenging activity.

Based on the results of in vitro qualitative screening, 39 isolates were selected. Most of them belonged to $S$. cerevisiae, which is the most commonly species in backslopped sourdoughs ${ }^{33}$. Such isolates were molecularly characterized at the strain level by the inter-delta region analysis, which had been previously detected as the best discriminating technique to type sourdough S. cerevisiae isolates ${ }^{19,34}$. Cluster analysis of the inter-delta profiles grouped all the S. cerevisiae isolates in a cluster showing a low similarity (44\%) with the two commercial baker's yeast strains, suggesting that our isolates could be autochthonous and did not derive from cross contamination by baker's yeasts. Moreover, a high intraspecific diversity was detected, consistently with Osimani et al. ${ }^{35}$ and Pulvirenti et al. ${ }^{36}$, who used the same method to characterize, at the strain level, S. cerevisiae yeasts isolated from sourdoughs from the Italian regions Marche and Sicily, respectively. Similar results were also obtained by Palla et al. ${ }^{19}$, who observed a high polymorphism among $77 \mathrm{~S}$. cerevisiae isolated from Tuscan sourdoughs.

The main role of yeasts in bread-making is gas production, which affects the volume of bread. Indeed, the most important trait, which is usually considered during yeast starter selection, is the ability to ferment sugars anaerobically with an adequate production of $\mathrm{CO}_{2}$, to ensure a uniform dough leavening ${ }^{37}$. S. cerevisiae is the species of choice in the baking industry due to its high fermentation capacity; indeed, it is characterized by a rapid consumption of sugars and a fast $\mathrm{CO}_{2}$ production, which are the most important attributes required to leaven the dough ${ }^{38}$. Here, almost all the selected isolates showed a high leavening ability, when inoculated in wheat and emmer flours. As expected, strains belonging to the $S$. cerevisiae species showed the best leavening performances compared to the other yeast genera and species. In particular, S. cerevisiae IMA D4Y, D17Y and D25Y showed a 


\begin{tabular}{|c|c|c|c|c|c|c|c|c|c|}
\hline Cereal flour & Yeast strains ${ }^{\mathrm{a}}$ & $\begin{array}{l}\text { CWBPAs }{ }^{\mathrm{b}}(\mathrm{mg} / \\
\mathrm{kg})\end{array}$ & $\begin{array}{l}\text { Hydroxybenzoic } \\
\text { acid (mg/kg) }\end{array}$ & $\begin{array}{l}\text { Vanillic acid } \\
(\mathrm{mg} / \mathrm{kg})\end{array}$ & $\begin{array}{l}\text { Caffeic acid } \\
(\mathrm{mg} / \mathrm{kg})\end{array}$ & $\begin{array}{l}\text { Syringic acid } \\
(\mathrm{mg} / \mathrm{kg})\end{array}$ & $\begin{array}{l}p \text {-coumaric } \\
\text { acid }(\mathrm{mg} / \mathrm{kg})\end{array}$ & $\begin{array}{l}\text { Ferulic acid } \\
(\mathrm{mg} / \mathrm{kg})\end{array}$ & \begin{tabular}{|l}
$\begin{array}{l}\text { Sinapic acid } \\
(\mathrm{mg} / \mathrm{kg})\end{array}$ \\
\end{tabular} \\
\hline \multirow{6}{*}{$\begin{array}{l}\text { Red-grained } \\
\text { Common wheat } \\
\text { (cv. Aubusson) }\end{array}$} & Control & $826 c$ & $3.00 \mathrm{~b}$ & $5.57 \mathrm{~b}$ & $7.52 \mathrm{a}$ & $2.76 \mathrm{~b}$ & $22.8 \mathrm{a}$ & $720 c$ & $64.7 \mathrm{a}$ \\
\hline & ZEUS IBA & $957 \mathrm{a}$ & $3.55 \mathrm{a}$ & $6.57 \mathrm{a}$ & $7.72 \mathrm{a}$ & $3.47 \mathrm{a}$ & $25.5 \mathrm{a}$ & $837 a$ & $72.5 \mathrm{a}$ \\
\hline & D20Y & $917 \mathrm{ab}$ & $3.66 \mathrm{a}$ & 6.10ab & $7.58 \mathrm{a}$ & 3.13ab & $23.8 \mathrm{a}$ & 810ab & $62.8 \mathrm{a}$ \\
\hline & D22Y & $886 \mathrm{~b}$ & $3.34 \mathrm{ab}$ & $5.96 \mathrm{~b}$ & $7.83 a$ & $2.98 \mathrm{~b}$ & $24.3 \mathrm{a}$ & $774 \mathrm{~b}$ & $66.8 \mathrm{a}$ \\
\hline & SEM & 13 & 0.12 & 0.15 & 0.35 & 0.11 & 0.7 & 12 & 2.1 \\
\hline & $\mathrm{P}(\mathrm{F})$ & 0.001 & 0.017 & 0.01 & 0.914 & 0.012 & 0.147 & 0.001 & \begin{tabular}{|l|}
0.051 \\
\end{tabular} \\
\hline \multirow{6}{*}{$\begin{array}{l}\text { Yellow-grained } \\
\text { common wheat } \\
\text { (cv. Bona vita) }\end{array}$} & Control & $858 \mathrm{a}$ & $3.94 \mathrm{c}$ & $7.16 \mathrm{a}$ & $6.41 \mathrm{a}$ & $6.22 \mathrm{~b}$ & $30.4 \mathrm{a}$ & $759 a$ & $45.0 \mathrm{a}$ \\
\hline & ZEUS IBA & $837 \mathrm{a}$ & $4.22 \mathrm{~b}$ & 7.11a & $6.88 \mathrm{a}$ & $6.7 \mathrm{a}$ & $28.4 \mathrm{a}$ & $727 \mathrm{a}$ & $55.9 \mathrm{a}$ \\
\hline & \begin{tabular}{|l|} 
L17Y \\
\end{tabular} & $896 a$ & $4.56 \mathrm{a}$ & $7.56 a$ & $7.02 \mathrm{a}$ & $6.99 a$ & $30.0 \mathrm{a}$ & $784 a$ & $55.8 \mathrm{a}$ \\
\hline & L22Y & $868 a$ & $4.4 \mathrm{ab}$ & 7.44a & $7.34 \mathrm{a}$ & $6.9 \mathrm{a}$ & $29.5 \mathrm{a}$ & 761a & $51.9 \mathrm{a}$ \\
\hline & SEM & 22 & 0.05 & 0.15 & 0.23 & 0.09 & 0.7 & 20 & 3.1 \\
\hline & $\mathrm{P}(\mathrm{F})$ & 0.35 & $<0.001$ & 0.186 & 0.115 & $<0.001$ & 0.27 & 0.33 & 0.11 \\
\hline \multirow{6}{*}{$\begin{array}{l}\text { Blue-grained } \\
\text { common wheat } \\
\text { (cv. Skorpion) }\end{array}$} & Control & $866 a$ & $5.29 \mathrm{~b}$ & $7.87 \mathrm{a}$ & $6.42 \mathrm{a}$ & $6.38 \mathrm{~b}$ & $39.0 \mathrm{a}$ & $768 \mathrm{a}$ & $33.1 \mathrm{~b}$ \\
\hline & ZEUS IBA & $890 a$ & $6.30 \mathrm{a}$ & $8.53 a$ & $6.87 \mathrm{a}$ & $7.8 \mathrm{a}$ & $40.4 \mathrm{a}$ & $782 a$ & $37.5 \mathrm{a}$ \\
\hline & \begin{tabular}{|l|} 
D8Y \\
\end{tabular} & $907 a$ & $5.80 \mathrm{ab}$ & $8.10 \mathrm{a}$ & $6.86 \mathrm{a}$ & $7.57 \mathrm{a}$ & $39.8 \mathrm{a}$ & $800 a$ & $39.4 \mathrm{a}$ \\
\hline & L6Y & 924a & $6.42 \mathrm{a}$ & $8.54 a$ & $6.56 a$ & $7.64 \mathrm{a}$ & $42.8 \mathrm{a}$ & $814 a$ & $37.7 \mathrm{a}$ \\
\hline & SEM & 19 & 0.2 & 0.27 & 0.21 & 0.19 & 1.2 & 18 & 0.9 \\
\hline & $\mathrm{P}(\mathrm{F})$ & 0.236 & 0.015 & 0.292 & 0.406 & 0.002 & 0.198 & 0.35 & 0.006 \\
\hline \multirow{6}{*}{$\begin{array}{l}\text { Emmer } \\
\text { (cv. Giovanni } \\
\text { Paolo) }\end{array}$} & Control & $588 \mathrm{a}$ & $2.33 \mathrm{~b}$ & $4.42 \mathrm{~b}$ & $4.48 \mathrm{a}$ & $2.48 \mathrm{~b}$ & $17.9 \mathrm{~b}$ & 524a & $33.0 \mathrm{a}$ \\
\hline & ZEUS IBA & $670 a$ & $3.35 a$ & $5.40 \mathrm{a}$ & $5.58 \mathrm{a}$ & $3.02 \mathrm{a}$ & $22 a$ & 594a & $36.6 \mathrm{a}$ \\
\hline & D18Y & $649 a$ & $3.06 a$ & $5.22 \mathrm{a}$ & $5.12 \mathrm{a}$ & $2.89 \mathrm{a}$ & 20.3ab & 576a & $36.7 \mathrm{a}$ \\
\hline & L22Y & $683 a$ & $3.37 \mathrm{a}$ & 5.41a & $5.58 \mathrm{a}$ & $3.06 a$ & $22.8 \mathrm{a}$ & $605 a$ & $37.6 \mathrm{a}$ \\
\hline & SEM & 21 & 0.1 & 0.19 & 0.28 & 0.08 & 1.0 & 19 & 2.1 \\
\hline & $\mathrm{P}(\mathrm{F})$ & 0.051 & $<0.001$ & 0.019 & 0.076 & 0.004 & 0.031 & 0.066 & \begin{tabular}{|l|}
0.447 \\
\end{tabular} \\
\hline \multirow{6}{*}{$\begin{array}{l}\text { Hull-less barley } \\
\text { (cv. Rondo) }\end{array}$} & Control & $985 a$ & $2.86 a$ & $7.22 \mathrm{~b}$ & $37.3 \mathrm{a}$ & $2.09 a$ & $32.9 \mathrm{a}$ & $884 a$ & $18.8 \mathrm{a}$ \\
\hline & ZEUS IBA & $1039 a$ & $3.58 \mathrm{a}$ & $9.25 \mathrm{a}$ & $38.3 a$ & $2.13 a$ & $33.7 \mathrm{a}$ & $932 a$ & $19.8 \mathrm{a}$ \\
\hline & L10Y & 994a & $3.08 \mathrm{a}$ & 8.61a & $36.6 \mathrm{a}$ & $1.98 \mathrm{a}$ & $33.3 \mathrm{a}$ & $890 a$ & 21.1a \\
\hline & L15Y & 1001a & $3.33 a$ & 8.92a & $38.1 \mathrm{a}$ & $2.22 \mathrm{a}$ & $32.6 \mathrm{a}$ & $894 a$ & $22.0 \mathrm{a}$ \\
\hline & SEM & 21 & 0.18 & 0.22 & 1.4 & 0.17 & 0.9 & 19 & 1.9 \\
\hline & $\mathrm{P}(\mathrm{F})$ & 0.372 & 0.099 & 0.001 & 0.794 & 0.81 & 0.827 & 0.323 & \begin{tabular}{|l|}
0.654 \\
\end{tabular} \\
\hline
\end{tabular}

Table 2. Cell wall-bound phenolic acids (CWBPAs) of five different cereal fermented doughs individually inoculated with selected yeast strains. Data are expressed on a dw basis. For each cereal type, means followed by different letters are significantly different, according to the Tukey's HSD test (the ANOVA level of significance is shown in the table). SEM standard error of the mean. ${ }^{a}$ Control, dough obtained from water and whole grain flour mixture, without yeast addition; ZEUS IBA, S. cerevisiae commercial baker's yeasts. ${ }^{\text {b Sum of }}$ the CWBPAs determined by means of the RP-HPLC/DAD.

significant higher leavening performance than S. cerevisiae commercial baker's yeast in doughs obtained using wheat flours, highlighting their efficiency as leavening agents. Similar results were found by Carbonetto et al. ${ }^{39}$, who reported that $K$. humilis strains never leavened dough as much as $S$. cerevisiae when singly inoculated in doughs. Moreover, our results showed that, contrary to S. cerevisiae commercial baker's yeast, $33 \%$ of strains were able to increase the volume of doughs made using barley, which is a cereal with a lesser ability to form a gluten complex than wheat, thus decreasing dough gas retention ${ }^{40}$.

Besides carbon dioxide production, during fermentation yeasts produce ethanol and secondary metabolites which influence the quality of fermented products ${ }^{41}$. Yeasts affect the flavour of bread producing different aroma precursors such as esters, aldehydes and ketones; moreover, they increase the shelf-life producing various acids and glycerol ${ }^{37}$, and affect the functional and nutritional properties of bread producing enzymes and antioxidant compounds ${ }^{31}$. As the characterization of yeast strains with high leavening ability and able to produce functional enzymes and antioxidant compounds may lead to the selection of functional starters, ten yeasts for each flour showing the best performance in vitro were selected and further analyzed in vivo for their functional features (phytase activity and polyphenol content). Overall, all the yeast strains showed phytase activity, with a high variability among doughs started with the different strains. In the commercial baker's yeast Zeus IBA phytase activity was strongly affected by the type of flour, highlighting the importance of selecting specific strains for each flour. Almost all the strains led to increases in sourdough total phenol contents, and at least one strain for each flour showed polyphenol contents significantly higher than those of the commercial baker's yeast.

These findings are consistent with the recent literature, which reported that yeasts play an important role in increasing the polyphenol content of cereal products by releasing bound and conjugated phenolic acids to their free form after cell wall degradation process ${ }^{42}$. The analysis of the single phenolic acids carried out on wholegrain 


\begin{tabular}{|c|c|c|c|c|c|c|c|c|}
\hline Cereal flour & Yeast strains ${ }^{\mathrm{a}}$ & $\mathrm{SPAs}^{\mathrm{b}}(\mathrm{mg} / \mathrm{kg})$ & $\begin{array}{l}\text { Hydroxybenzoic } \\
\text { acid (mg/kg) }\end{array}$ & $\begin{array}{l}\text { Vanillic acid (mg/ } \\
\text { kg) }\end{array}$ & $\begin{array}{l}\text { Syringic acid (mg/ } \\
\text { kg) }\end{array}$ & $\begin{array}{l}\text { p-coumaric acid } \\
(\mathrm{mg} / \mathrm{kg})\end{array}$ & $\begin{array}{l}\text { Ferulic acid (mg/ } \\
\text { kg) }\end{array}$ & \begin{tabular}{|l}
$\begin{array}{l}\text { Sinapic acid } \\
(\mathrm{mg} / \mathrm{kg})\end{array}$ \\
\end{tabular} \\
\hline \multirow{6}{*}{$\begin{array}{l}\text { Red-grained } \\
\text { common wheat } \\
\text { (cv. Aubusson) }\end{array}$} & Control & $148 \mathrm{~b}$ & $5.71 \mathrm{c}$ & $8.55 b$ & $3.82 \mathrm{~b}$ & $3.24 \mathrm{~b}$ & $89.5 \mathrm{a}$ & $37.1 \mathrm{c}$ \\
\hline & ZEUS IBA & $161 \mathrm{a}$ & $7.89 \mathrm{a}$ & $9.13 a$ & $4.82 \mathrm{a}$ & $3.51 \mathrm{a}$ & $91.7 \mathrm{a}$ & $43.6 \mathrm{a}$ \\
\hline & \begin{tabular}{|l|} 
D20Y \\
\end{tabular} & $157 \mathrm{a}$ & $7.33 \mathrm{~b}$ & $9.07 \mathrm{a}$ & $4.66 \mathrm{a}$ & $3.30 \mathrm{~b}$ & 92.1a & $40.8 \mathrm{~b}$ \\
\hline & D22Y & $162 \mathrm{a}$ & 7.60ab & $9.08 \mathrm{a}$ & $4.61 \mathrm{a}$ & $3.42 \mathrm{ab}$ & $95.7 \mathrm{a}$ & $42.0 \mathrm{ab}$ \\
\hline & SEM & 2 & 0.14 & 0.13 & 0.07 & 0.05 & 1.3 & 0.5 \\
\hline & $\mathrm{P}(\mathrm{F})$ & 0.004 & $<0.001$ & 0.033 & $<0.001$ & 0.019 & 0.053 & $<0.001$ \\
\hline \multirow{6}{*}{$\begin{array}{l}\text { Yellow-grained } \\
\text { common wheat } \\
\text { (cv. Bona vita) }\end{array}$} & Control & $153 \mathrm{~b}$ & $7.46 \mathrm{~b}$ & $12.3 \mathrm{~b}$ & $9.04 \mathrm{~b}$ & $2.98 \mathrm{a}$ & $82.2 \mathrm{a}$ & $39.1 \mathrm{~b}$ \\
\hline & ZEUS IBA & $162 \mathrm{a}$ & $10.14 \mathrm{a}$ & $13.6 \mathrm{a}$ & $11.09 \mathrm{a}$ & $3.18 \mathrm{a}$ & $80.1 \mathrm{a}$ & $44.4 \mathrm{a}$ \\
\hline & \begin{tabular}{|l} 
L17Y \\
\end{tabular} & $167 \mathrm{a}$ & $10.30 \mathrm{a}$ & $13.7 \mathrm{a}$ & $11.73 a$ & $3.36 \mathrm{a}$ & $83.3 \mathrm{a}$ & $44.6 \mathrm{a}$ \\
\hline & L22Y & $167 \mathrm{a}$ & $10.03 a$ & $13.8 \mathrm{a}$ & $11.41 \mathrm{a}$ & $3.29 \mathrm{a}$ & $83.7 \mathrm{a}$ & $44.8 \mathrm{a}$ \\
\hline & SEM & 2 & 0.11 & 0.2 & 0.25 & 0.12 & 1 & 0.6 \\
\hline & $\mathrm{P}(\mathrm{F})$ & 0.002 & $<0.001$ & 0.001 & $<0.001$ & 0.22 & 0.11 & $<0.001$ \\
\hline \multirow{6}{*}{$\begin{array}{l}\text { BLUE-grained } \\
\text { common wheat } \\
\text { (cv. Skorpion) }\end{array}$} & Control & $146 \mathrm{~b}$ & $6.89 \mathrm{c}$ & $11.3 \mathrm{~b}$ & $9.56 \mathrm{~b}$ & $3.2 \mathrm{~b}$ & $80.4 \mathrm{a}$ & $35.1 \mathrm{~b}$ \\
\hline & ZEUS IBA & $162 \mathrm{a}$ & $9.85 \mathrm{ab}$ & $12.7 \mathrm{a}$ & $12.5 \mathrm{a}$ & $3.43 \mathrm{ab}$ & $82.0 \mathrm{a}$ & $41.2 \mathrm{a}$ \\
\hline & D8Y & $159 a$ & $9.54 \mathrm{~b}$ & $12.7 \mathrm{a}$ & $12.2 \mathrm{a}$ & $3.39 \mathrm{ab}$ & $79.6 \mathrm{a}$ & $41.2 \mathrm{a}$ \\
\hline & \begin{tabular}{|l|} 
L6Y \\
\end{tabular} & $162 a$ & $9.96 \mathrm{ab}$ & $12.9 \mathrm{a}$ & $12.8 \mathrm{a}$ & $3.59 \mathrm{a}$ & $80.9 \mathrm{a}$ & $41.4 \mathrm{a}$ \\
\hline & SEM & 2 & 0.05 & 0.16 & 0.25 & 0.07 & 0.8 & 0.8 \\
\hline & $\mathrm{P}(\mathrm{F})$ & 0.002 & $<0.001$ & $<0.001$ & $<0.001$ & 0.023 & 0.266 & 0.001 \\
\hline \multirow{6}{*}{$\begin{array}{l}\text { Emmer } \\
\text { (cv. Giovanni } \\
\text { Paolo) }\end{array}$} & Control & $112 c$ & $5.33 \mathrm{~b}$ & $7.76 \mathrm{~b}$ & $2.53 a$ & $3.33 c$ & $54.4 \mathrm{c}$ & $38.5 c$ \\
\hline & ZEUS IBA & $131 \mathrm{~b}$ & $7.09 a$ & $9.28 \mathrm{a}$ & $2.94 \mathrm{a}$ & $3.66 \mathrm{~b}$ & $63.4 \mathrm{~b}$ & $44.4 \mathrm{ab}$ \\
\hline & \begin{tabular}{|l|} 
D18Y \\
\end{tabular} & $135 \mathrm{ab}$ & $7.03 a$ & $9.44 \mathrm{a}$ & $2.83 a$ & $4.20 \mathrm{a}$ & $67.6 \mathrm{ab}$ & $43.5 \mathrm{~b}$ \\
\hline & L22Y & $141 \mathrm{a}$ & $7.23 a$ & $9.27 \mathrm{a}$ & $3.00 \mathrm{a}$ & $3.97 \mathrm{a}$ & $69.9 \mathrm{a}$ & $48.1 \mathrm{a}$ \\
\hline & SEM & 2 & 0.08 & 0.17 & 0.12 & 0.07 & 1.2 & 1 \\
\hline & $\mathrm{P}(\mathrm{F})$ & $<0.001$ & $<0.001$ & $<0.001$ & 0.096 & $<0.001$ & $<0.001$ & 0.001 \\
\hline \multirow{6}{*}{$\begin{array}{l}\text { Hull-less barley } \\
\text { (cv. Rondo) }\end{array}$} & control & $126 \mathrm{c}$ & $3.00 \mathrm{~b}$ & $8.03 b$ & $1.53 b$ & $6.09 \mathrm{ab}$ & $94.8 \mathrm{~b}$ & $12.1 \mathrm{~b}$ \\
\hline & ZEUS IBA & $140 \mathrm{a}$ & $4.00 \mathrm{a}$ & $9.99 \mathrm{a}$ & $1.94 \mathrm{a}$ & $6.55 a$ & $103 a$ & $13.8 \mathrm{a}$ \\
\hline & L10Y & $130 \mathrm{bc}$ & $3.92 \mathrm{a}$ & $9.75 a$ & $1.88 \mathrm{a}$ & $5.85 b c$ & $95 \mathrm{~b}$ & $13.7 \mathrm{a}$ \\
\hline & L15Y & $133 \mathrm{~b}$ & $3.98 \mathrm{a}$ & 9.91a & $1.94 \mathrm{a}$ & $5.34 \mathrm{c}$ & $98.5 \mathrm{~b}$ & 13.4a \\
\hline & SEM & 1 & 0.08 & 0.16 & 0.06 & 0.14 & 1 & 0.3 \\
\hline & $\mathrm{P}(\mathrm{F})$ & 0.001 & $<0.001$ & $<0.001$ & 0.006 & 0.002 & 0.001 & 0.006 \\
\hline
\end{tabular}

Table 3. Soluble (free and conjugated forms) phenolic acids (SPAs) of five different cereal fermented doughs individually inoculated with selected yeast strains. Data are expressed on a dw basis. For each cereal type, means followed by different letters are significantly different, according to the Tukey's HSD test (the ANOVA

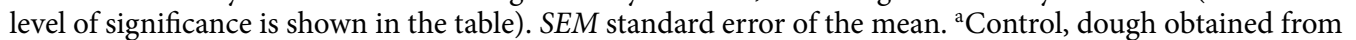
water and whole grain flour mixture, without yeast addition; ZEUS IBA, S. cerevisiae commercial baker's yeasts. ${ }^{b}$ Sum of the SPAs determined by means of the RP-HPLC/DAD.

doughs showed that all the selected yeasts significantly increased the soluble, free and conjugated forms of phenolic acids. Among them, each single compound showed a significant increase, although at a different extent: within the main SPAs, sinapic acid showed a higher average increase $(+15 \%)$ compared to ferulic acid $(+6 \%)$, while among the minor compounds hydroxybenzoic and syringic acids increased by 35 and 24\%, respectively. Our data are consistent with those reported by Skrajda-Brdak et al. ${ }^{43}$, who observed that free benzoic acids were preferentially accumulated in yeast fermented breads. In addition, SPA increases in fermented dough were higher in cereals characterized by a greater wholegrain flour SPA content, in particular for emmer. Since SPAs can be easier absorbed by the intestinal cells compared to bounded ones, their increase as a consequence of yeast fermentation may positively affect the amount of phenolics accessible in the upper gastrointestinal $\operatorname{tract}^{44}$.

SPA increases detected after dough fermentation did not correspond to a reduction in CWBPAs, which significantly increased in all the selected yeast strains compared to the control. This result was particularly evident for hydroxybenzoic and syringic acids, and for conventional red-grained common wheat cultivars. The CWBPAs increase could be ascribed to the production of phenolic compounds by yeasts, that could contribute to enhance their overall content in fermented doughs ${ }^{45}$.

In addition to phenolic acids, also anthocyanins increased in the fermented doughs, showing different amounts depending on the selected strain. Such data may have a functional significance as anthocyanins in pigmented wheat were recognized as health-enhancing substances due to their antioxidant, anti-inflammatory, anticancer and hypoglycemic activities ${ }^{46}$.

Several yeast species can produce different types of carotenoids such as astaxanthin, $\beta$-carotene, $\gamma$-carotene, torulene and torularhod ${ }^{47}$. In the present study, yeast fermentation did not seem to affect the content of lutein and zeaxanthin, the main carotenoids in wholegrain flour of yellow-grained wheat and emmer. 


\begin{tabular}{|c|c|c|c|c|c|c|}
\hline Cereal flour & Yeast strains ${ }^{\mathrm{a}}$ & $\begin{array}{l}\text { TAC (mg Cy-3- } \\
\text { glc/kg) }\end{array}$ & Lutein (mg/kg) & $\begin{array}{l}\text { Zeaxanthin (mg/ } \\
\text { kg) }\end{array}$ & $\begin{array}{l}\text { AC-FRAP (mmol } \\
\text { TE/kg) }\end{array}$ & $\begin{array}{l}\text { AC-ABTS } \\
(\mathrm{mmol} \mathrm{TE} / \mathrm{kg})\end{array}$ \\
\hline \multirow{6}{*}{$\begin{array}{l}\text { Red-grained } \\
\text { common wheat } \\
\text { (cv. Aubusson) }\end{array}$} & Control & & & & $11.5 \mathrm{~b}$ & $19.9 \mathrm{a}$ \\
\hline & ZEUS IBA & & & & $12.6 \mathrm{a}$ & $20.5 \mathrm{a}$ \\
\hline & D20Y & & & & $12.5 \mathrm{a}$ & $19.8 \mathrm{a}$ \\
\hline & $\mathrm{D} 22 \mathrm{Y}$ & & & & $13.1 \mathrm{a}$ & $20.6 \mathrm{a}$ \\
\hline & SEM & & & & 0.2 & 0.6 \\
\hline & $\mathrm{P}(\mathrm{F})$ & & & & 0.013 & 0.713 \\
\hline \multirow{6}{*}{$\begin{array}{l}\text { Yellow-grained } \\
\text { common wheat } \\
\text { (cv. Bona vita) }\end{array}$} & Control & & $1.13 \mathrm{a}$ & $0.168 \mathrm{a}$ & $12.2 \mathrm{a}$ & $21.2 \mathrm{a}$ \\
\hline & ZEUS IBA & & $1.21 \mathrm{a}$ & $0.158 \mathrm{a}$ & $11.8 \mathrm{a}$ & $20.7 \mathrm{a}$ \\
\hline & L17Y & & $1.13 \mathrm{a}$ & $0.162 \mathrm{a}$ & $12.7 \mathrm{a}$ & $21.6 \mathrm{a}$ \\
\hline & L22Y & & $1.14 \mathrm{a}$ & $0.157 \mathrm{a}$ & $11.8 \mathrm{a}$ & $21.0 \mathrm{a}$ \\
\hline & SEM & & 0.03 & 0.005 & 0.4 & 0.5 \\
\hline & $\mathrm{P}(\mathrm{F})$ & & 0.18 & 0.51 & 0.28 & 0.62 \\
\hline \multirow{6}{*}{$\begin{array}{l}\text { Blue-grained } \\
\text { common wheat } \\
\text { (cv. Skorpion) }\end{array}$} & Control & $17.7 \mathrm{c}$ & & & $10.9 \mathrm{~b}$ & $20.2 \mathrm{a}$ \\
\hline & ZEUS IBA & $20.4 \mathrm{a}$ & & & $11.9 \mathrm{ab}$ & $21.3 \mathrm{a}$ \\
\hline & \begin{tabular}{|l|} 
D8Y \\
\end{tabular} & $19.3 \mathrm{~b}$ & & & $11.7 \mathrm{ab}$ & $21.8 \mathrm{a}$ \\
\hline & L6Y & $20.3 \mathrm{a}$ & & & $12.4 \mathrm{a}$ & $21.3 \mathrm{a}$ \\
\hline & SEM & \begin{tabular}{|l|}
0.1 \\
\end{tabular} & & & 0.3 & 0.6 \\
\hline & $\mathrm{P}(\mathrm{F})$ & $<0.001$ & & & 0.031 & 0.318 \\
\hline \multirow{6}{*}{$\begin{array}{l}\text { Emmer } \\
\text { (cv. Giovanni } \\
\text { Paolo) }\end{array}$} & Control & & $1.05 \mathrm{a}$ & $0.153 \mathrm{a}$ & $6.8 \mathrm{~b}$ & $20.3 \mathrm{a}$ \\
\hline & ZEUS IBA & & $1.04 \mathrm{a}$ & $0.142 \mathrm{a}$ & $7.9 \mathrm{a}$ & $19.9 \mathrm{a}$ \\
\hline & D18Y & & $1.07 \mathrm{a}$ & $0.153 a$ & 7.4ab & $20.8 \mathrm{a}$ \\
\hline & L22Y & & $1.07 \mathrm{a}$ & $0.141 \mathrm{a}$ & $8.1 \mathrm{a}$ & $19.6 \mathrm{a}$ \\
\hline & SEM & & 0.03 & 0.004 & 0.2 & 0.4 \\
\hline & $\mathrm{P}(\mathrm{F})$ & & 0.794 & 0.115 & 0.006 & 0.232 \\
\hline \multirow{6}{*}{$\begin{array}{l}\text { Hull-less barley } \\
\text { (cv. Rondo) }\end{array}$} & Control & & & & $25.1 \mathrm{~b}$ & $44.9 \mathrm{a}$ \\
\hline & \begin{tabular}{|l|} 
ZEUS IBA \\
\end{tabular} & & & & $25.3 \mathrm{~b}$ & $40.9 \mathrm{a}$ \\
\hline & L10Y & & & & $27.0 \mathrm{a}$ & $45.6 \mathrm{a}$ \\
\hline & L15Y & & & & $25.6 \mathrm{ab}$ & $40.2 \mathrm{a}$ \\
\hline & SEM & & & & 0.4 & 3.5 \\
\hline & $\mathrm{P}(\mathrm{F})$ & & & & 0.036 & 0.627 \\
\hline
\end{tabular}

Table 4. Total anthocyanin (TAC), xanthophyll (lutein and zeaxanthin) content and antioxidant capacity (AC) of five different cereal fermented doughs individually inoculated with selected yeast strains. Data are expressed on a dw basis. For each cereal type, means followed by different letters are significantly different, according to the Tukey's HSD test (the ANOVA level of significance is shown in the table). SEM standard error of the mean. ${ }^{a}$ Control, dough obtained from water and whole grain flour mixture, without yeast addition; ZEUS IBA, $S$. cerevisiae commercial baker's yeasts.

In accordance with the changes in the content of antioxidant compounds, a significant increase in total antioxidant activity was detected in fermented doughs, analyzed by means of the FRAP method. Such increases could be ascribed also to other compounds, i.e. small bioactive peptides produced by the action of proteolytic yeasts during dough fermentation ${ }^{31}$.

Combining all the results, for each of the five flours we selected two yeast strains with the highest leavening, phytase and antioxidant activities. It is interesting to note that different strains were detected for each flour, thus highlighting the importance of selecting specific strains for each cereal flour, each characterized by different biochemical and qualitative traits. Indeed, such strains had previously shown variable pro-technological and functional traits when individually used to ferment commercial soft and durum wheat flours ${ }^{19}$, confirming that the activity and production of enzymes during fermentation depend on the specificity of the substrate ${ }^{31}$.

In conclusion, this work highlighted the importance of a specific selection of yeast strains for wholegrain flours, obtained from different cereals or cultivars, in order to enhance the pro-technological, nutritional and nutraceutical traits of fermented doughs. With the aim of producing healthy baked goods, the overall strategy should entail the appropriate integration of wholegrain flour from cereals and cultivars with a higher content of bioactive compounds and antioxidants with selected yeast starter strains conferring the highest functional properties to fermented doughs.

\section{Materials and methods}

Grain cultivation and milling. In this study five different wholegrain flours were analyzed. Three varieties of an ordinary bread-making winter common wheat were used: a conventional red-grained variety (cv. Aubusson, Limagrain Italia SpA), a yellow-grained variety rich in carotenoids (cv. Bona Vita, Osivo a. s., Slovakia) and 
a blue-grained variety rich in anthocyanins (cv. Skorpion, Agricultural Research Institute Kromeriz, Ltd., Czech Republic). In addition, a winter emmer variety (cv. Giovanni Paolo, Apsovsementi s.p.a, Italy) and a hull-less spring barley variety (cv. Rondo, Società Italiana Sementi s.p.a, Italy) were also analyzed.

The five cereal cultivars were grown side by side on the same experimental field located in Carmagnola, Italy, (Piedmont; $44^{\circ} 50^{\prime} \mathrm{N}, 7^{\circ} 40^{\prime} \mathrm{E}$; altitude $245 \mathrm{~m}$ ) during the growing season $2016 / 2017$. The plot size for each cultivar was $5 \times 100 \mathrm{~m}\left(500 \mathrm{~m}^{2}\right)$ and the ordinary crop technique of the growing area was applied. Wholegrain flour from each cultivar was obtained by means of a single-stream natural stone milling process (Molino Tomatis S.N.C, Niella Tanaro, Italy), without any sifting processes.

Functional characterization of flours. The wholegrain flour from each cultivar was analyzed for SPA and CWBPA, xanthophylls, TAC and total antioxidant capacity. The extraction and quantification of soluble (free and conjugated) and cell wall-bound phenolic acids was performed according to the procedure proposed by $\mathrm{Li}$ et al. ${ }^{48}$ with some modifications as reported by Giordano et al. ${ }^{49}$. Briefly, one hundred and twenty-five milligrams of each sample were mixed in $1 \mathrm{~mL}$ of an 80:20 (v/v) ethanol:water solution and centrifuged at $10,600 \times \mathrm{g}$ for $10 \mathrm{~min}$, in order to remove the supernatants. A second extraction was carried out with 80:20 (v/v) ethanol:water solution. Supernatants were collected, hydrolyzed with $2 \mathrm{M} \mathrm{NaOH}(400 \mu \mathrm{L})$ for $2 \mathrm{~h}$ under continuous stirring at $4{ }^{\circ} \mathrm{C}$, acidified with $\mathrm{HCl}$, then SPAs were extracted with $500 \mu \mathrm{L}$ of ethyl acetate.

The pellet remaining after the first part of the extraction was hydrolyzed for $4 \mathrm{~h}$ under continuous stirring at $4{ }^{\circ} \mathrm{C}$ by adding $2 \mathrm{M} \mathrm{NaOH}(400 \mu \mathrm{L})$. After acidification with $\mathrm{HCl}$, the CWBPA were extracted with $800 \mu \mathrm{L}$ of ethyl acetate and then centrifuged at $10,600 \times g$ for $2 \mathrm{~min}$.

Phenolic extracts were filtered through a $0.2 \mu \mathrm{m}$ filter and then analyzed by an Agilent 1200 Series (Agilent Technologies, Santa Clara, CA, USA) high-performance liquid chromatograph coupled to an Agilent 1200 Series diode array detector. Separations were carried out using a $150 \times 4.6 \mathrm{~mm}, 5 \mu \mathrm{m}$ particle size, Gemini RP-18 column (Phenomenex, Torrance, CA, USA).

The total anthocyanin content (TAC) was determined only for the stone-milled flour obtained from the blue-variety of common wheat (cv. Skorpion). Each sample $(1 \mathrm{~g})$ was extracted using $8 \mathrm{~mL}$ of ethanol acidified with $1 \mathrm{~N} \mathrm{HCl}(85: 15, \mathrm{v} / \mathrm{v})$ for $30 \mathrm{~min}$. The absorbance was measured after centrifugation at 20,800 $\times \mathrm{g}$ for $2 \mathrm{~min}$ at $540 \mathrm{~nm}$ as reported by Siebenhandl et al. ${ }^{50}$. TAC was expressed as mg cyanidin-3-O-glucoside (Cy-3-glc) equivalents/kg of sample $(\mathrm{dw})$.

The extraction and quantification of xanthophylls was performed as previously reported by Giordano et al. ${ }^{49}$. The analysis was performed only for the stone-milled flours obtained from the yellow-grained variety of common wheat (cv. Bona Vita) and from the emmer variety (cv. Giovanni Paolo). trans- $\beta$-Apo- 8 '-carotenal was used as internal standard to ensure that losses due to the extraction method were accounted for.

The antioxidant capacity was determined by means of the ferric reducing antioxidant power (FRAP) and the ABTS [2,2'-Azino-bis (3-ethylbenzthiazoline-6-sulfonic acid)] assays adapted into QUENCHER method as described by Serpen et al. ${ }^{51}$.

Microorganisms, media and growth conditions. The 139 yeasts used in this study were maintained in the International Microbial Archives (IMA) of the Microbiology Labs of the Department of Agriculture, Food and Environment (DAFE) of the University of Pisa (Supplementary Table S3 online) and originated as follows: 78 strains were previously isolated from wheat Tuscan sourdoughs ${ }^{19}, 3 \mathrm{~S}$. cerevisiae strains from PDO Tuscan bread sourdough ${ }^{27}$. The other 58 yeasts were isolated from different Italian sourdoughs (43) and from Boza, a cereal-based fermented drink (15), following the method described in Palla et al. ${ }^{27}$. Along with such isolates, two commercial baker's yeasts-S. cerevisiae Zeus IBA (ZEUS IBA srl) and S. cerevisiae Lievitalia (Lesaffre Italia spa) - and four reference strains (Supplementary Table S3 online) were used. The isolates were grown in Yeast Extract Peptone Dextrose agar (YEPD: 1\% yeast extract, $1 \%$ bacteriological peptone, $2 \%$ dextrose and $2 \%$ agar) at $28^{\circ} \mathrm{C}$ for $48 \mathrm{~h}$.

In vitro functional characterization of yeast isolates. The 139 yeasts, along with the reference strains, were preliminary analyzed by in vitro screening for their functional traits, i.e. phytase and antioxidant activities. Phytase activity was evaluated measuring the production of halo zones around the microbial colonies on a Phytate Screening Medium (PSM: $1 \%$ D-glucose, $0.4 \% \mathrm{Na}$-phytate, $0.2 \% \mathrm{CaCl}_{2}, 0.5 \% \mathrm{NH}_{4} \mathrm{NO}_{3}, 0.05 \% \mathrm{KCl}$, $0.05 \% \mathrm{MgSO}_{4} \cdot 7 \mathrm{H}_{2} \mathrm{O}, 0.001 \% \mathrm{FeSO}_{4} \cdot 7 \mathrm{H}_{2} \mathrm{O}, 0.001 \% \mathrm{MnSO}_{4} \cdot \mathrm{H}_{2} \mathrm{O}, 1.5 \%$ agar, pH 7.0 ) as described in Palla et al. ${ }^{27}$. In particular, the isolates were grown overnight at $28^{\circ} \mathrm{C}$ in $4 \mathrm{~mL}$ of PSM broth medium by shaking, and the microbial cultures were then spotted on the agar plate and incubated at $28{ }^{\circ} \mathrm{C}$ for $48 \mathrm{~h}$. To eliminate false positive results, plates were counterstained using $2 \%(\mathrm{w} / \mathrm{v})$ cobalt chloride and $6.25 \%(\mathrm{w} / \mathrm{v})$ ammonium molybdate as described by Bae et al..$^{52}$ and by Pepe et al. ${ }^{53}$. The phytase ability of isolates was calculated as the difference between the total diameter (colony + halo zone) and the colony diameter.

The antioxidant activity was determined by the free radical scavenging capacity using the stable 2,2-diphenyl1-picrylhydrazyl radical (DPPH). Yeasts were grown at $25^{\circ} \mathrm{C}$ in Wheat Flour Hydrolysate (WFH) by shaking for $24 \mathrm{~h}$. The WFH was produced as described by Coda et al. ${ }^{54}$. Four $\mathrm{mL}$ of each microbial culture were centrifuged at $8,000 \mathrm{rpm}$ for $10 \mathrm{~min}$, and $75 \mu \mathrm{L}$ of supernatant were transferred into a test tube containing $1 \mathrm{~mL}$ of distilled water and $25 \mu \mathrm{L}$ of DPPH solution. WFH not inoculated with yeast culture was used as a control. Absorbance at $517 \mathrm{~nm}$ was measured after $30 \mathrm{~min}$ of incubation in the dark by a spectrophotometer (Varian Cary $1 \mathrm{E}$ UV-Vis, Palo alto, CA, USA). The free radical scavenging capacity was quantified as follows: DPPH scavenging activity $(\%)=[$ (blank absorbance - sample absorbance $) /$ blank absorbance $] \times 100$ and expressed as nmol TEAC/mL (Trolox equivalents of antioxidant capacity). 
Molecular characterization of selected isolates. Based on in vitro screening results, the best 55 performing yeasts were selected. Among them, 31 had been previously identified ${ }^{19,27}$ and the remaining 24 were identified by the amplification of the D1/D2 domains of the 26S rRNA gene and sequencing. DNA of isolates was extracted from microbial liquid cultures grown at $25^{\circ} \mathrm{C}$ in YEPD broth, using a "MasterPure Yeast DNA Purification Kit" (Epicentre) as described by Agnolucci et al. ${ }^{55}$. PCR reaction was carried out using NL1 (5'GCA TAT CAA TAA GCG GAG GAA AAG-3') and NL4 (5'-GGT CCG TGT TTC AAG ACG G-3') primers ${ }^{56}$ in a final volume of $50 \mu \mathrm{L}$, containing $5 \mu \mathrm{L}$ of 10X DyNAzyme Buffer (Finnzymes, Thermofisher, Milan, Italy), $0.2 \mathrm{mM}$ of each dNTPs (BioLabs), $0.5 \mu \mathrm{M}$ of each primer (Eurofins Genomics, Ebersberg, Germany), $0.625 \mathrm{U}$ of Taq DyNAzyme II DNA polymerase (Finnzymes, Thermofisher, Milan, Italy) and using 10-20 ng of DNA. The amplifications were carried out with an iCycler-iQ Multicolor Real-Time PCR Detection System (Bio-Rad) using the following conditions: $94^{\circ} \mathrm{C}$ initial denaturation for $1 \mathrm{~min} ; 35$ amplification cycles of $30 \mathrm{~s}$ at $94{ }^{\circ} \mathrm{C}, 30 \mathrm{~s}$ at $58{ }^{\circ} \mathrm{C}, 30 \mathrm{~s}$ at $72{ }^{\circ} \mathrm{C}$; final extension at $72{ }^{\circ} \mathrm{C}$ for $5 \mathrm{~min}$. The presence of amplicons was confirmed by electrophoresis in $1.5 \%(w / v)$ agarose gel stained with $0.5 \mu \mathrm{g} / \mathrm{mL}$ of REALSAFE Nucleic Acid Staining (Real laboratory SL, Valencia, Spain). All gels were visualized by UV and captured as TIFF format files by the UVI 1D v. 16.11a program for FIRE READER V4 gel documentation systems (Uvitec Cambridge, Eppendorf). PCR products were purified with the UltraClean PCR CleanUp kit (MO BIO Laboratories, Carlsbad, CA, USA) according to the manufacturer's protocol, quantified and 5' sequenced by Eurofins Genomics (Ebersberg, Germany). Sequences were analyzed using BLAST on the NCBI web (https://blast.ncbi.nlm.nih.gov/Blast.cgi). The related sequences were collected and aligned using MUSCLE ${ }^{57,58}$, and phylogenetic trees were constructed using the NeighborJoining method based on the kimura 2-parameter mode ${ }^{59}$ in Mega X software (https://www.megasoftware.net/) with 1000 bootstrap replicates $^{60}$. The sequences were submitted to the GenBank of National Center for Biotechnology Information (NCBI), under the accession numbers from MT269548 to MT269571.

According to the identification results, 39 yeasts were selected and molecularly characterized. The intraspecific diversity of such isolates, along with the two commercial baker's yeasts, was carried out by inter-delta region analysis. Amplification reaction was performed using $\delta_{1}\left(5^{\prime}\right.$-CAAAATTCACCTATA/TTCTCA- $\left.3^{\prime}\right)$ and $\delta_{2}\left(5^{\prime}-\right.$ GTGGATTTTTATTCCAACA-3') ${ }^{61}$ primers (Eurofins Genomics, Ebersberg Germany) and 160 ng of DNA, as reported in Palla et al. ${ }^{19}$. All gels were visualized and captured as previously described. Inter-delta profiles were digitally processed and analyzed with the BioNumerics software version 7.6 (Applied Maths, St-Martens-Latem, Belgium). Profiles were compared using the band matching tool with a position tolerance and optimization of $0.5 \%$, and similarity was calculated using the Dice's coefficient. For cluster analysis, unpaired group method with arithmetic average (UPGMA) trees with highest resampling support, in a permutation sample of size 200, were constructed. The reproducibility of fingerprints was assessed on four randomly selected strains.

Leavening ability of selected yeast strains. The 39 selected yeasts were further analyzed for their leavening ability, an important pro-technological feature, by in vivo screening using the five different wholegrain flours previously described. To this aim, yeast strains were cultivated into YEPD broth at $25^{\circ} \mathrm{C}$ overnight; cells were then harvested following centrifugation $\left(10,000 \times\right.$ yeast strains were cultivated into YEPD broth at $25^{\circ} \mathrm{C}$ overnight; cells were then harvested following centrifugation $\left(10,000 \times \mathrm{g}, 10 \mathrm{~min}, 4^{\circ} \mathrm{C}\right)$, washed in sterile salinepeptone water $(0.9 \% \mathrm{NaCl}, 0.1 \%$ bacteriological peptone, Oxoid, Milan, Italy), re-suspended in tap water at the cell density of ca. 6.0-7.0 Log cfu/mL and used as starters for dough fermentation. Three different batches of each flour $(62.5 \mathrm{~g})$ and tap water $(26.5 \mathrm{~mL})$, containing the above cellular suspension of each yeast (cell density in the dough of ca. $6.0 \mathrm{log} \mathrm{cfu} / \mathrm{g}$ ), were pooled and used to prepare $100 \mathrm{~g}$ of dough with a dough yield of 160 (dough yield $=$ dough weight $\times 100 /$ flour weight $)$ supplemented with chloramphenicol $(0.1 \mathrm{~g} / \mathrm{L})$. Mixing was done manually for $5 \mathrm{~min}$. Doughs were fermented at $30^{\circ} \mathrm{C}$ for $24 \mathrm{~h}$, according to the common temperature used in sourdough preparation at artisanal and industrial levels ${ }^{62}$. Not inoculated doughs (control) and Zeus IBA and Lievitalia commercial baker's yeasts were used as references. The values of dough $\mathrm{pH}$, before and after fermentation, were determined by a pHmeter (Medidor PH BASIC 20, Crison, Milan, Italy) with a penetration probe. During fermentation, the increase in volume $\left(\Delta \mathrm{V}, \mathrm{cm}^{3}\right)$ was manually monitored every two hours and the leavening performance calculated as the increase in volume during the time of fermentation $\left(\Delta \mathrm{V} / \mathrm{t}, \mathrm{cm}^{3} / \mathrm{h}\right)^{19,63}$.

In vivo functional properties of selected strains. The ten best performing yeasts for each flour were selected and further analyzed for their functional traits, i.e. phytase activity and content of polyphenols, by in vivo screening.

Water/salt-soluble extracts (WSE) of fermented doughs were prepared according to Weiss et al. ${ }^{64}$. Phytase activity was assessed by monitoring the rate of hydrolysis of $p$-nitrophenyl phosphate ( $p$-NPP) as described by Rizzello et al. ${ }^{65}$. The assay mixture contained $200 \mu \mathrm{L}$ of $1.5 \mathrm{mM} p$-NPP (Sigma, 104-0) (final concentration) in $0.2 \mathrm{M} \mathrm{Na}$-acetate, $\mathrm{pH} 5.2$, and $400 \mu \mathrm{L}$ of WSE diluted tenfold. The mixture was incubated at $45^{\circ} \mathrm{C}$ for $10 \mathrm{~min}$ and the reaction was stopped by adding $600 \mu \mathrm{L}$ of $0.1 \mathrm{M} \mathrm{NaOH}$. The $p$-nitrophenol released was determined by measuring the absorbance at $405 \mathrm{~nm}$. One unit (U) of activity was defined as the amount of enzyme required to liberate $1 \mu \mathrm{mol} / \mathrm{min}$ of $p$-nitrophenol under the assay conditions.

The analysis of the total phenol contents was carried out on the methanolic extracts (ME) of fermented doughs by monitoring the reaction between phenols and the Folin-Ciocalteu reagent. In order to obtain the ME, two and half grams of each dough were mixed with $15 \mathrm{ml}$ of $80 \%$ methanol. The mixture was sonicated for 30 min, with a Bransonic 3510 ultrasonic apparatus (Branson, Danbury, CT, USA), and centrifuged at 10,000 $\times \mathrm{g}$ for $30 \mathrm{~min}$ at $4{ }^{\circ} \mathrm{C}$. ME were transferred into test tubes and stored at $-20^{\circ} \mathrm{C}$ before analysis. The concentration of total phenols was determined as described by Slinkard and Singleton ${ }^{66}$, with some modifications. The reaction mixture contained $50 \mu \mathrm{L}$ of ME, $250 \mu \mathrm{L}$ of Folin-Ciocalteu reagent (Sigma Chemical Co.) and $450 \mu \mathrm{L}$ of distilled water. After $10 \mathrm{~min}$ of incubation at room temperature, $1.25 \mathrm{~mL}$ of a $20 \%$ sodium carbonate solution were added. 
The mixture was incubated at room temperature for $20 \mathrm{~min}$ and the absorbance at $735 \mathrm{~nm}$ was determined. The concentration of total phenols was calculated as gallic acid equivalents (GAE).

The combination of leavening ability, phytase activity and total phenol content allowed the detection of the two best performing strains for each flour. Such selected fermented doughs, along with the dough fermented by the commercial baker's yeast Zeus IBA and control dough, were further analyzed for their antioxidant capacity, phenolic acid, xanthophyll and anthocyanin contents using the methods described above.

Statistical analysis. Analyses were carried out in triplicate with three biological replicates for each condition. The SPSS version 23 software (IBM Corp., Armonk, NY, USA) was used for the statistical analysis of phenolic acids, total anthocyanins, xanthophylls and total antioxidant capacity in the stone-milled cereal flours and in the selected fermented doughs of each cultivar. SPSS was also used for the statistical analysis of the leavening ability, phytase activity and phenol content of doughs singly inoculated with the yeast strains. Data were subjected to one-way analysis of variance (ANOVA) followed by Tukey's HSD test at a 99\% confidence level to evaluate the differences among strain traits. When data did not fit ANOVA assumptions, the Welch robust test of equality of means was performed.

The normalized values of leavening ability, phytase activity and phenol content were subjected to permutation analysis using PermutMatrix ver. 1.9.4 $4^{67,68}$.

\section{Data availability}

The datasets analysed during the current study are available from the corresponding author on reasonable request.

Received: 14 April 2020; Accepted: 16 July 2020

Published online: 30 July 2020

\section{References}

1. Tamang, J. P., Watanabe, K. \& Holzapfel, W. H. Diversity of microorganisms in global fermented foods and beverages. Front. Microbiol. 7, 377. https://doi.org/10.3389/fmicb.2016.00377 (2016).

2. Gobbetti, M., De Angelis, M., Corsetti, A. \& Di Cagno, R. Biochemistry and physiology of sourdough lactic acid bacteria. Trends Food Sci. Technol. 16, 57-69 (2005).

3. Poutanen, K., Flander, L. \& Katina, K. Sourdough and cereal fermentation in a nutritional perspective. Food Microbiol. 26, 693-699 (2009).

4. Vogel, R. F. et al. Non-dairy lactic fermentations: The cereal world. Antonie Van Leeuwenhoek 76, 403-411 (1999).

5. Scazzina, F., Del Rio, D., Pellegrini, N. \& Brighenti, F. Sourdough bread: Starch digestibility and postprandial glycemic response. J. Cereal Sci. 49, 419-421 (2009).

6. Cappelle, S., Guylaine, L., Gänzle, M. \& Gobbetti, M. History and social aspects of sourdough. In Handbook on Sourdough Biotechnology (eds Gobbetti, M. \& Ganzle, G. M.) 105-154 (Springer, Berlin, 2013).

7. Gobbetti, M. The sourdough microflora: Interactions of lactic acid bacteria and yeasts. Trends Food Sci. Technol. 9, 267-274 (1998).

8. De Vuyst, L., Harth, H., Van Kerrebroeck, S. \& Leroy, F. Yeast diversity of sourdoughs and associated metabolic properties and functionalities. Int. J. Food Microbiol. 19, 26-34 (2016).

9. Gänzle, M. G. \& Ripari, V. Composition and function of sourdough microbiota: From ecological theory to bread quality. Int. J. Food Microbiol. 239, 19-25 (2016).

10. Gobbetti, M., Rizzello, C. G., Di Cagno, R. \& De Angelis, M. How the sourdough may affect the functional features of leavened baked goods. Food Microbiol. 37, 30-40 (2014).

11. Rizzello, C. G., Coda, R. \& Gobbetti, M. Use of sourdough fermentation and nonwheat flours for enhancing nutritional and healthy properties of wheat-based foods. In Fermented Foods in Health and Disease Prevention (eds Frías, J. et al.) 433-452 (Academic Press, Cambridge, 2016).

12. Katina, K. \& Poutanen, K. Nutritional aspects of cereal fermentation with lactic acid bacteria and yeast. In Handbook on Sourdough Biotechnology (eds Gobbetti, M. \& Gänzle, M.) 229-244 (Springer, Berlin, 2013).

13. Kariluoto, S. et al. In situ enrichment of folate by microorganisms in beta-glucan rich oat and barley matrices. Int. J. Food Microbiol. 176, 38-48 (2014).

14. Liukkonen, K. H. et al. Process-induced changes on bioactive compounds in whole grain rye. Proc. Nutr. Soc. 62, 117-122 (2003).

15. Moore, J. et al. Effects of solid-state yeast treatment on the antioxidant properties and protein and fiber compositions of common hard wheat bran. J. Agric. Food Chem. 55, 10173-10182 (2007).

16. Wang, T., He, F. \& Chen, G. Improving bioaccessibility and bioavailability of phenolic compounds in cereal grains through processing technologies: a concise review. J. Funct. Foods 7, 101-111 (2014).

17. Greppi, A. et al. Phytase-producing capacity of yeasts isolated from traditional African fermented food products and PHYPk gene expression of Pichia kudriavzevii strains. Int. J. Food Microbiol. 205, 81-89 (2015).

18. Türk, M., Sandberg, A. S., Carlsson, N. G. \& Andlid, T. Inositol hexaphosphate hydrolysis by Baker's yeast. Capacity, kinetics, and degradation products. J. Agric. Food Chem. 48, 100-104 (2000).

19. Palla, M. et al. Exploitation of autochthonous Tuscan sourdough yeasts as potential starters. Int. J. Food Microbiol. 302, 59-68 (2019).

20. Adom, K. K. \& Liu, R. H. Antioxidant activity of grains. J. Agric. Food Chem. 50, 6182-6187 (2002).

21. Bordiga, M. et al. Phenolics characterization and antioxidant activity of six different pigmented Oryza sativa L. cultivars grown in Piedmont (Italy). Food Res. Int. 65, 282-290 (2014).

22. Giordano, D., Beta, T., Gagliardi, F. \& Blandino, M. Influence of agricultural management on phytochemicals of colored corn genotypes (Zea mays L.) - Part II: Sowing time. J. Agric. Food Chem. 66, 4309-4318 (2018).

23. Giordano, D. et al. Bioactive compound and antioxidant activity distribution in rollermilled and pearled fractions of conventional and pigmented wheat varieties. Food Chem. 233, 483-491 (2017).

24. Zanoletti, M. et al. Debranning of purple wheat: Recovery of anthocyanin-rich fractions and their use in pasta production. $L W T$ Food Sci. Technol. 75, 663-669 (2017).

25. Blandino, M. et al. Hull-less barley pearling fractions: Nutritional properties and the effect on the functional and technological quality of bread-making. J. Cereal Sci. 65, 48-56 (2015).

26. Guerzoni, M. E., Serrazanetti, D. I., Vernocchi, P. \& Gianotti, A. Physiology and biochemistry of sourdough yeasts. In Handbook on Sourdough Biotechnology (eds Gobbetti, M. \& Gänzle, M.) 155-181 (Springer, Berlin, 2013).

27. Palla, M., Cristani, C., Giovannetti, M. \& Agnolucci, M. Identification and characterization of lactic acid bacteria and yeasts of PDO Tuscan bread sourdough by culture dependent and independent methods. Int. J. Food Microbiol. 250, 19-26 (2017). 
28. Nuobariene, L., Hansen, ÅS. \& Arneborg, N. Isolation and identification of phytase-active yeasts from sourdoughs. LWT Food Sci. Technol. 48, 190-196 (2012).

29. Menezes, A. G. T. et al. Probiotic potential, antioxidant activity, and phytase production of indigenous yeasts isolated from indigenous fermented foods. Probiotics Antimicrob. Proteins 12, 280-288 (2020).

30. Campos-Vega, R., Loarca-Piña, G. \& Oomah, B. D. Minor components of pulses and their potential impact on human health. Food Res. Int. 43, 461-482 (2010).

31. Rai, A. K., Pandey, A. \& Sahoo, D. Biotechnological potential of yeasts in functional food industry. Trends Food Sci. Technol. 83, 129-137 (2019).

32. Gazi, M. R., Hoshikuma, A., Kanda, K., Murata, A. \& Kato, F. Detection of free radical scavenging activity in yeast culture. Bull. Fac. Agric. Saga Univ. 86, 67-74 (2001).

33. Van Kerrebroeck, S., Maes, D. \& De Vuyst, L. Sourdoughs as a function of their species diversity and process conditions, a metaanalysis. Trends Food Sci. Technol. 68, 152-159 (2017).

34. Palla, M., Cristani, C., Giovannetti, M. \& Agnolucci, M. Large genetic intraspecific diversity of autochthonous lactic acid bacteria and yeasts isolated from PDO Tuscan bread sourdough. Appl. Sci. 10, 1043. https://doi.org/10.3390/app10031043 (2020).

35. Osimani, A. et al. Lactic acid bacteria and yeasts from wheat sourdoughs of the Marche region. Ital. J. Food Sci. 21, 269-286 (2009).

36. Pulvirenti, A., Solieri, L., Gullo, M., De Vero, L. \& Giudici, P. Occurrence and dominance of yeast species in sourdough. Lett. Appl. Microbiol. 38, 113-117 (2004).

37. Heitmann, M., Zannini, E. \& Arendt, E. Impact of Saccharomyces cerevisiae metabolites produced during fermentation on bread quality parameters: A review. Crit. Rev. Food Sci. Nutr. 58, 1152-1164 (2018).

38. Zhou, N. et al. Kazachstania gamospora and Wickerhamomyces subpelliculosus: Two alternative baker's yeasts in the modern bakery. Int. J. Food Microbiol. 250, 45-58 (2017).

39. Carbonetto, B. et al. Interactions between Kazachstania humilis yeast species and lactic acid bacteria in sourdough. Microorganisms. 8, 240. https://doi.org/10.3390/microorganisms8020240 (2020).

40. Dhingra, S. \& Jood, S. Organoleptic and nutritional evaluation of wheat breads supplemented with soybean and barley flour. Food Chem. 77, 479-488 (2001).

41. Agnolucci, M., Tirelli, A., Cocolin, L. \& Toffanin, A. Brettanomyces bruxellensis yeasts: Impact on wine and winemaking. World J. Microbiol. Biotechnol. 33, 180 (2017).

42. Ogunremi, O. R., Sanni, A. I. \& Agrawal, R. Hypolipidaemic and antioxidant effects of functional cereal-mix produced with probiotic yeast in rats fed high cholesterol diet. J. Funct. Foods 17, 742-748 (2015).

43. Skrajda-Brdak, M., Konopka, I., Tańska, M. \& Czaplicki, S. Changes in the content of free phenolic acids and antioxidative capacity of wholemeal bread in relation to cereal species and fermentation type. Eur. Food Res. Technol. 245, 2247-2256 (2019).

44. Calinoiu, L. F. \& Vodnar, D. C. Whole grains and phenolic acids: A review on bioactivity, functionality, health benefits and bioavailability. Nutrients. 10, 1615. https://doi.org/10.3390/nu10111615 (2018).

45. Bhanja Dey, T., Chakraborty, S., Jain, K. K., Abha Sharma, A. \& Kuhad, R. C. Antioxidant phenolics and their microbial production by submerged and solid state fermentation process: A review. Trends Food Sci. Technol. 53, 60-74 (2016).

46. He, J. \& Giusti, M. M. Anthocyanins: Natural colorants with health-promoting properties. Annu. Rev. Food Sci. Technol. 1, 163-187 (2010).

47. Mannazzu, I. S., Landolfo, T. L. \& Buzzini, P. Red yeasts and carotenoid production: Outlining a future for non-conventional yeasts of biotechnological interest. World J. Microbiol. Biotechnol. 31, 1665-1673 (2015).

48. Li, L., Shewry, P. R. \& Ward, J. L. Phenolic acids in wheat varieties in the HEALTHGRAIN diversity screen. J. Agric. Food Chem. 56, 9732-9739 (2008).

49. Giordano, D., Reyneri, A., Locatelli, M., Coïsson, J. D. \& Blandino, M. Distribution of bioactive compounds in pearled fractions of tritordeum. Food Chem. 301, 125228. https://doi.org/10.1016/j.foodchem.2019.125228 (2019).

50. Siebenhandl, S. et al. Phytochemical profile of main antioxidants in different fractions of purple and blue wheat, and black barley. J. Agric. Food Chem. 55, 8541-8547 (2007).

51. Serpen, A., Gökmen, V. \& Fogliano, V. Solvent effects on total antioxidant capacity of foods measured by direct QUENCHER procedure. J. Food Compost. Anal. 26, 52-57 (2012).

52. Bae, H. D., Yanke, L. J., Cheng, K.-J. \& Selinger, L. B. A novel staining method for detecting phytase activity. J. Microbiol. Methods 39, 17-22 (1999).

53. Pepe, O. et al. Technological and molecular diversity of Lactobacillus plantarum strains isolated from naturally fermented sourdoughs. System. Appl. Microbiol. 27, 443-453 (2004).

54. Coda, R. et al. Long-term fungal inhibitory activity of water-soluble extracts of Phaseolus vulgaris cv. Pinto and sourdough lactic acid bacteria during bread storage. Appl. Environ. Microbiol. 74, 7391-7398 (2008).

55. Agnolucci, M., Scarano, S., Rea, F., Toffanin, A. \& Nuti, M. Detection of DekkeraBrettanomyces bruxellensis in pressed Sangiovese grapes by real time PCR. Ital. J. Food Sci. 19, 155-166 (2007).

56. Kurtzman, C. P. \& Robnett, C. J. Identification and phylogeny of ascomycetous yeasts from analysis of nuclear large subunit (26S) ribosomal DNA partial sequences. Antonie Van Leeuwenhoek 73, 331-371 (1998).

57. Edgar, R. C. MUSCLE: a multiple sequence alignment method with reduced time and space complexity. BMC Bioinf. 5, 113. https ://doi.org/10.1186/1471-2105-5-113 (2004).

58. Edgar, R. C. MUSCLE: multiple sequence alignment with high accuracy and high throughput. Nucleic Acids Res. 32, 1792-1797 (2004).

59. Kimura, M. A simple method for estimating evolutionary rate of base substitutions through comparative studies of nucleotide sequences. J. Mol. Evol. 16, 111-120 (1980).

60. Kumar, S., Stecher, G., Li, M., Knyaz, C. \& Tamura, K. MEGA X: Molecular evolutionary genetics analysis across computing platforms. Mol. Biol. Evol. 35, 1547-1549 (2018).

61. Ness, F., Lavallèe, F., Dubourdieu, D., Aigle, M. \& Dulau, L. Identification of yeast strains using the Polymerase Chain Reaction. J. Sci. Food Agric. 62, 89-94 (1993).

62. Minervini, F. et al. Lactic acid bacterium and yeast microbiotas of 19 sourdoughs used for traditional/typical Italian breads: interactions between ingredients and microbial species diversity. Appl. Environ. Microbiol. 78, 1251-1264 (2012).

63. Minervini, F., Pinto, D., Di Cagno, R., De Angelis, M. \& Gobbetti, M. Scouting the application of sourdough to frozen dough bread technology. J. Cereal Sci. 54, 296-304 (2011).

64. Weiss, W., Vogelmeier, C. \& Görg, A. Electrophoretic characterization of wheat grain allergens from different cultivars involved in Bakers' asthma. Electrophoresis 14, 805-816 (1993).

65. Rizzello, C. G., Nionelli, L., Coda, R., De Angelis, M. \& Gobbetti, M. Effect of sourdough fermentation on stabilisation, and chemical and nutritional characteristics of wheat germ. Food Chem. 119, 1079-1089 (2010).

66. Slinkard, K. \& Singleton, V. L. Total phenol analysis: automation and comparison with manual methods. Am. J. Enol. Vitic. 28, 49-55 (1997).

67. Eisen, M. B., Spellman, P. T., Brown, P. O. \& Botstein, D. Cluster analysis and display of genome-wide expression patterns. Proc. Natl. Acad. Sci. USA 95, 14863-14868 (1998).

68. Caraux, G. \& Pinloche, S. PermutMatrix: A graphical environment to arrange gene expression profiles in optimal linear order. Bioinformatics 21, 1280-1281 (2005). 


\section{Acknowledgments}

This study was supported by the Italian Ministry of Education, University and Research (MIUR) programme PRIN 2015 (Grant number 2015SSEKFL) "Processing for healthy cereal foods". The authors would like to thank Dr. Caterina Cristani for her support in DNA sequencing analysis.

\section{Author contributions}

Experiments were conceived by M.G., A.R., M.A, M.B. and M.F.Q. and conducted by M.P., A.G, C.S., D.G. All authors wrote the manuscript.

\section{Competing interests}

The authors declare no competing interests.

\section{Additional information}

Supplementary information is available for this paper at https://doi.org/10.1038/s41598-020-69774-6.

Correspondence and requests for materials should be addressed to M.A. or M.G.

Reprints and permissions information is available at www.nature.com/reprints.

Publisher's note Springer Nature remains neutral with regard to jurisdictional claims in published maps and institutional affiliations.

(c) (i) Open Access This article is licensed under a Creative Commons Attribution 4.0 International License, which permits use, sharing, adaptation, distribution and reproduction in any medium or format, as long as you give appropriate credit to the original author(s) and the source, provide a link to the Creative Commons license, and indicate if changes were made. The images or other third party material in this article are included in the article's Creative Commons license, unless indicated otherwise in a credit line to the material. If material is not included in the article's Creative Commons license and your intended use is not permitted by statutory regulation or exceeds the permitted use, you will need to obtain permission directly from the copyright holder. To view a copy of this license, visit http://creativecommons.org/licenses/by/4.0/.

(C) The Author(s) 2020 